Document downloaded from:

http://hdl.handle.net/10251/103236

This paper must be cited as:

Molines, J.; Herrera Gamboa, MP.; Medina, JR. (2018). Estimations of wave forces on crown walls based on wave overtopping rates. Coastal Engineering. 132:50-62. doi:10.1016/j.coastaleng.2017.11.004

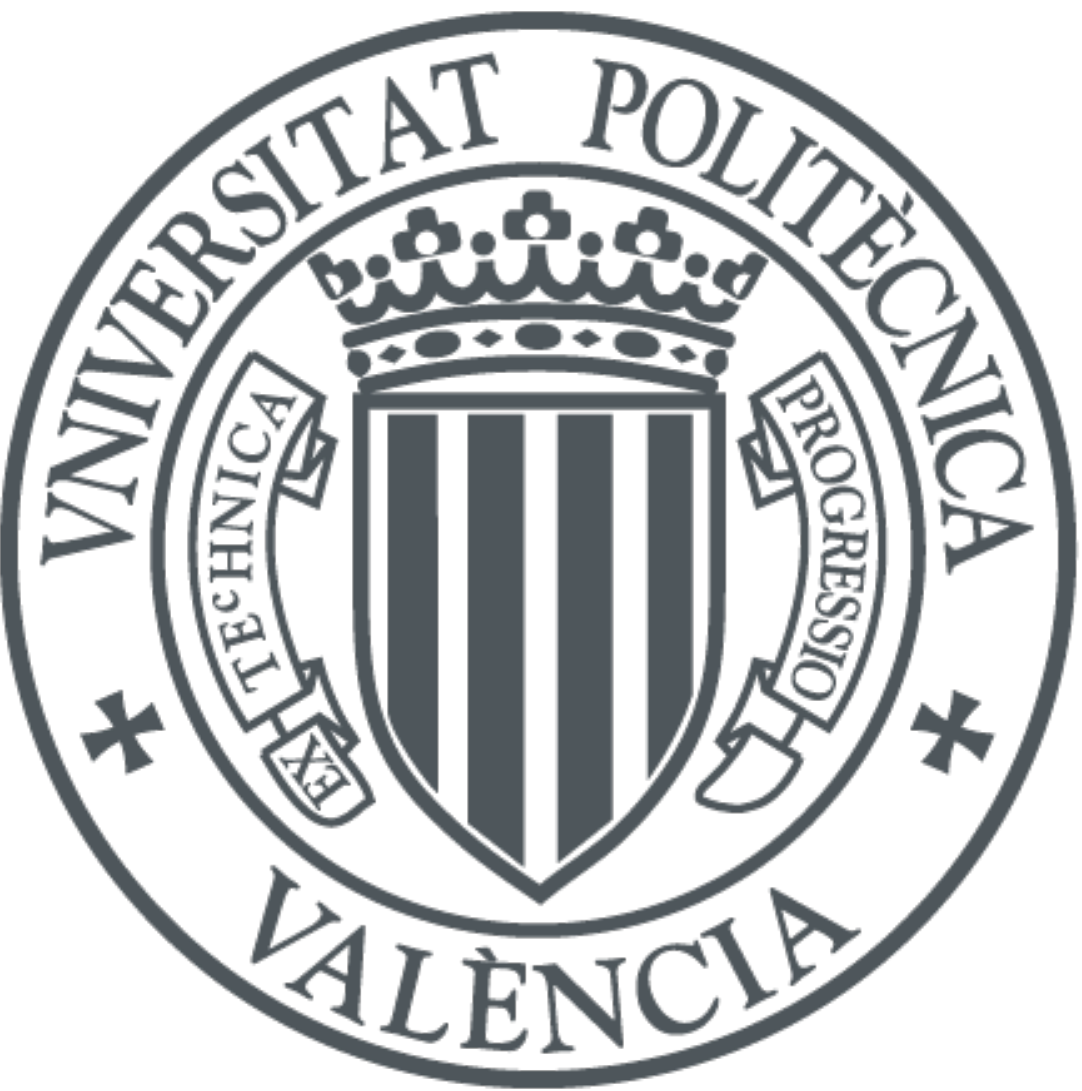

The final publication is available at

https://doi.org/10.1016/j.coastaleng.2017.11.004

Copyright Elsevier

Additional Information 


\title{
Estimations of wave forces on crown walls based on wave overtopping
}

\section{rates}

\author{
Jorge Molines $^{a, *}$, Maria P. Herrera ${ }^{b}$ and Josep R. Medina ${ }^{c}$ \\ a Assistant Professor, Dept. of Transportation, Universitat Politècnica de València, Camino de Vera s/n, 46022 \\ Valencia, Spain. E-mail: jormollo@upv.es (*corresponding author) \\ b Research Assistant, Dept. of Transportation, Universitat Politècnica de València, Camino de Vera s/n, 46022 \\ Valencia, Spain \& Consulting Engineer at Ingeomar, C/ Maximiliano Thous 20, 46009 Valencia, Spain. E-mail: \\ mahergam@upv.es \\ C Professor, Dept. of Transportation, Universitat Politècnica de València, Camino de Vera s/n, 46022 Valencia, Spain. \\ E-mail: jrmedina@upv.es
}

Keywords: crown wall, mound breakwater, wave forces, wave overtopping, foundation level

\section{Highlights:}

- Wave overtopping involves the structural response of the breakwater, whereas standard climatic or geometric variables do not consider the breakwater performance.

- 274 wave overtopping small-scale tests were used to obtain new wave force and overturning estimators with $30 \%<\mathrm{rMSE}<41 \%$.

- Horizontal wave forces and overturning moments are highly influenced by wave overtopping; the higher the wave overtopping rates, the lower the crown wall stability. 
- Up-lift pressure is dependent on the foundation level; the higher the foundation level, the lower the up-lift pressure.

- If wave overtopping is one order of magnitude higher, the wave forces and overturning moments on the crown wall increase between $11 \%$ and $60 \%$, considerably reducing the crown wall stability.

\section{Abstract}

In this study, seven input variables are used to estimate wave forces on the crown wall, and explanatory variables are ranked using neural network techniques. 274 smallscale 2D tests, including both wave overtopping and pressure on crown-wall measurements, were used to calibrate the wave force predictors. Wave overtopping (log Q) was the most relevant variable to estimate horizontal wave forces and overturning moments, while the relative foundation level $\left(F_{d} / L_{o p}\right)$ was the most relevant variable to estimate wave up-lift forces. The new wave force estimators showed prediction errors slightly higher than the formulas given in the literature, but using fewer parameters and explanatory variables. The range of application of the new formulas is $1.67<R_{d} /\left(\gamma_{\mathrm{f}} H_{m 0}\right)<6.55,1.39<\xi_{0 p}<7.77,0.36<\gamma_{\mathrm{f}} R_{u 0.1 \%} / R_{c}<1.41,0.00<\left(R_{c^{-}}\right.$ $\left.A_{c}\right) / C_{h}<0.59,2.64<\sqrt{L_{m} / G_{c}}<6.54,0.00<F_{c} / L_{o p}<0.03$ and $-6.00<\log Q<-2.78$. Compared to pressure on crown walls, the mean wave overtopping rate is relatively easy to measure in small-scale tests and prototypes. The new estimators of wave forces on the crown wall can be used to indirectly calculate forces on models when only overtopping rates are measured. If wave overtopping is one order of magnitude higher, the wave 
forces and overturning moments on the crown wall increase between $11 \%$ and $60 \%$, considerably reducing the crown wall stability.

\section{Introduction}

The crest elevation affects construction costs, overtopping rates and the visual impact of the breakwater. The design of mound breakwaters must ensure lower overtopping discharge than the tolerable limits for port operations and structural stability. A concrete crown wall is commonly designed to increase the crest freeboard and decrease the consumption of quarry materials. The crown wall also improves the accessibility to the breakwater and must withstand wave loads and other forces. Fig. 1 illustrates a cross section of a conventional mound breakwater with a crown wall and toe berm.

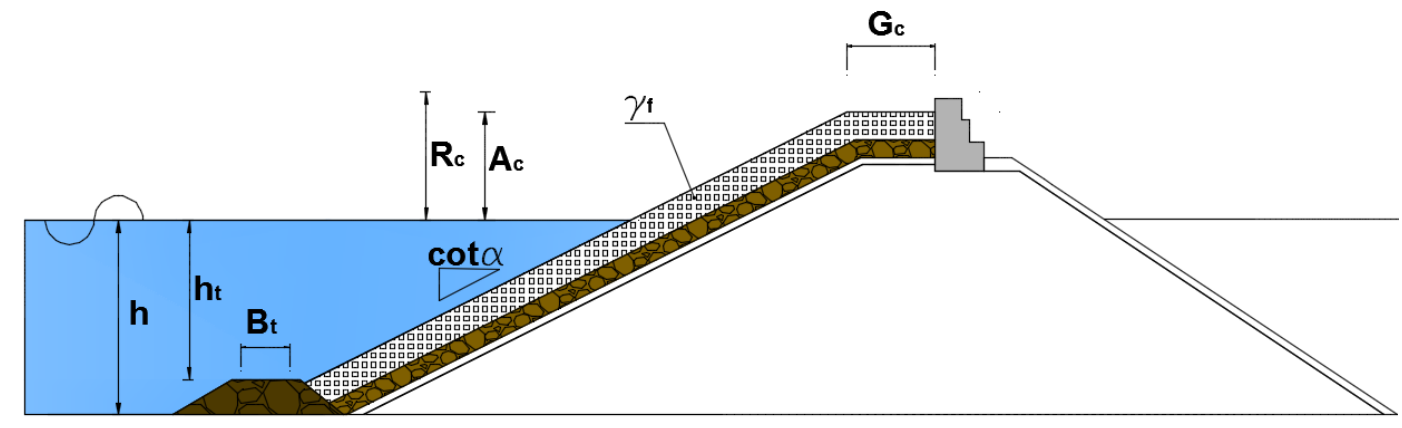

Fig. 1. Conventional mound breakwater cross section.

$R_{c}$ is the crown wall crest freeboard; $A_{c}$ is the armor crest freeboard; $G_{c}$ is the armor crest berm width; $\cot \alpha$ is the armor slope; $h$ is the water depth in front of the breakwater; $h_{t}$ is the water depth at the toe of the breakwater; $B_{t}$ is the width of the toe berm, and $\gamma_{f}$ is the roughness factor to consider the type of armor. 
Hamilton and Hall [1] noted that during exposure to moderate wave storms, the magnitude of the wave forces on the crown wall was roughly proportional to wave height. However, once the waves were large enough to generate significant wave overtopping rates, the wave forces on the crown wall seemed to have an upper limit that remained approximately constant and independent of the wave height.

Pedersen [2] conducted a sound analysis of wave overtopping and wave forces on crown walls of mound breakwaters. When the overtopping rate was significant, wave forces increased roughly proportional to the square of the crown wall height. When the crown wall crest freeboard was high enough to prevent overtopping, forces maintained an approximate constant value.

From the conceptual point of view, wave run-up over a slope may be considered a common cause for both wave overtopping and wave forces on crown walls. Wave overtopping and loads on crown walls are relevant if the virtual run-up is higher than the crown wall crest freeboard. Günback and Ergin [3], Pedersen [2] and Martín et al. [4] used virtual wave run-up to estimate wave forces on crown walls. It is obvious that wave forces on crown walls are related to the same variables that affect wave overtopping, such as the crown wall crest freeboard, crest berm width or type of armor. This study focuses attention on the explicit relationships between wave forces on crown walls and wave overtopping discharges. From the conceptual point of view, this study changes the virtual wave run-up for the wave overtopping as the key variable to estimate wave forces and overturning moments on the crown wall. It is not possible to measure virtual run-up and, compared to wave forces on crown wall, overtopping discharge can be measured easily in small-scale tests and prototypes. 
Therefore, the overtopping rate is a reasonable explanatory variable to estimate forces on the crown wall.

The formulas given in the literature to estimate wave forces and overturning moments on crown walls do not explicitly consider certain parameters such as the core permeability which affects wave run-up and overtopping. Moreover, existing methods to estimate wave forces on crown walls show high dispersion on results when using different formulas (see Negro et al. [5]). Wave overtopping is a variable relatively easy to define and measure by researchers and practitioners with widely accepted prediction tools such as the CLASH Neural Network (see Van Gent et al. [6] and Deltares [7]).

In this study, new formulas are developed to estimate wave forces on crown walls, based on the mean wave overtopping discharges, using 274 data from small-scale 2D tests conducted by Pedersen [2] and Molines [8]. The new formulas are valuable to design the crown geometry of mound breakwaters considering both overtopping discharges and crown wall stability. This paper is structured as follows. First, the literature related to wave overtopping and wave forces on crown walls is reviewed. Second, a list of possible explanatory variables for wave forces on crown walls is analyzed. Third, the experimental data are described in detail. Fourth, a neural network technique to develop new formulas is presented and the new wave force and overturning moment estimators are calculated. Fifth, the new formulas are compared with existing ones. Sixth, a sensitivity analysis is conducted and the influence of mean wave overtopping discharges on wave forces is characterized. Seventh, an example of application is provided and finally, general conclusions are drawn. 


\section{Literature review on wave overtopping and wave loads}

\subsection{Wave overtopping on mound breakwaters}

Several prediction methods are given in the literature to estimate wave overtopping on mound breakwaters, from simple explicit formulas to complex neural network tools. Eq. (1) proposed by Van der Meer and Janssen [9] is a well-known formula in which dimensionless wave overtopping is dependent on the crown wall crest freeboard $\left(R_{c}\right)$, the significant wave height at the toe $\left(H_{m 0}\right)$ and two reduction factors to account for the armor type and oblique wave attack $\left(\gamma_{\mathrm{f}}\right.$ and $\gamma_{\beta}$, respectively).

$\frac{q}{\sqrt{g \cdot H_{m 0}^{3}}}=0.2 \exp \left(-2.6 \cdot \frac{R_{c}}{H_{m 0}} \cdot \frac{1}{\gamma_{f} \gamma_{\beta}}\right)$

Pedersen [2] tested rock-, cube-, and Dolos-armored breakwaters with irregular waves. This author concluded that wider crest berms reduced wave overtopping. Eq. (2) summarizes the prediction method reported in Pedersen [2] with $f($ rocks $)=f($ Dolos $)=1$, $f($ cubes, 2-layer randomly placed) $=3$.

$\frac{q}{\sqrt{g H_{m 0}^{3}}}=3.2 \cdot 10^{-5} \frac{L_{0 m}^{2}}{T_{m} \sqrt{g H_{m 0}^{3}}} \frac{H_{c}^{5}}{R_{c}^{3} A_{c} G_{c} \cot \alpha} \cdot f($ armor $)$

where $T_{m}$ is mean wave period, $L_{0 m}=g T_{m}^{2} /(2 \pi)$ is the deepwater wavelength, $H_{s}$ is the significant wave height at the toe, $A_{c}, R_{c}, G_{c}$ and cot $\alpha$ are defined in Fig. 1.

Eq. (3) given by the EurOtop [10] manual uses the reduction factor $\mathrm{Cr}$ given by Besley [11] to include the influence of a permeable crest berm $\left(G_{c}\right)$ on wave overtopping if $G_{c}>3 D_{n 50}$ (where $D_{n 50}$ is the armor unit equivalent cube size length or nominal diameter). 


$$
\begin{aligned}
& C r=\min \left[1.0 ; 3.06 \cdot \exp \left(-1.5 \cdot \frac{G_{c}}{H_{m 0}}\right)\right] \\
& \frac{q}{\sqrt{g \cdot H_{m 0}^{3}}}=C r \cdot 0.2 \exp \left(-2.6 \cdot \frac{R_{c}}{H_{m 0}} \cdot \frac{1}{\gamma_{f} \gamma_{\beta}}\right)
\end{aligned}
$$

Smolka et al. [12] measured wave overtopping and wave loads on the crown wall based on small-scale 2D tests with double-layer randomly-placed cube-armored and single- and double-layer Cubipod-armored mound breakwaters in non-breaking conditions. The overtopping formula proposed by Smolka et al. [12] is:

$\frac{q}{\sqrt{g \cdot H_{m 0}^{3}}}=0.2 \cdot \exp \left(0.53 \xi_{0 p}-3.27 \cdot \frac{A_{c}}{R_{c}}-2.16 \frac{R_{c}}{H_{m 0}} \cdot \frac{1}{\gamma_{f}}\right)$

where $\xi_{0 p}=\tan \alpha /\left[2 \pi H_{m o} / g T_{p}^{2}\right]^{1 / 2}$ is the Iribarren number corresponding to the peak period $\left(T_{p}\right), \gamma_{f}$ [cube, 2-layer] $=0.50, \gamma_{f}$ [Cubipod, 1-layer] $=0.46$ and $\gamma_{f}$ [Cubipod, $2-$ layer $]=0.44, A_{c}$ and $R_{c}$ are defined in Fig. 1.

Eq. (5) given by Van de Meer and Bruce [13] and EurOtop [14] improved the performance of Eq. (1) in the range $0<R_{c} / H_{m 0}<0.5$, for non-breaking conditions: $\frac{q}{\sqrt{g \cdot H_{m 0}^{3}}}=0.09 \cdot \exp \left(-\left(1.5 \cdot \frac{R_{c}}{H_{m 0}} \cdot \frac{1}{\gamma_{f} \gamma_{\beta}}\right)^{1.3}\right)$

Van der Meer and Bruce [13] and EurOtop [14] noted that Eq. (5) provided overtopping estimations similar to Eq. (1), but better estimations for low and zero crown wall freeboards $\left(R_{c} / H_{m 0}<0.5\right)$.

The CLASH Project [15] collected more than 10,000 overtopping experimental data and proposed a neural network tool (see Deltares [7]) to accurately predict wave overtopping for any kind of breakwater (see Van Gent et al. [6]). Molines and Medina [16] proposed an overtopping estimator given by Eq. (6) that emulated the behavior of 
the CLASH Neural Network (see Van Gent et al. [6]) with explicit relationships between explanatory variables and wave overtopping discharges.

$$
Q_{M M}=\frac{q}{\sqrt{g \cdot H_{m 0}^{3}}}=\exp \left(\lambda_{2} \cdot \lambda_{3} \cdot \lambda_{4} \cdot \lambda_{5} \cdot \lambda_{6}\left[-1.6-2.6 \cdot \frac{R_{c}}{H_{m 0}} \cdot \frac{1}{\gamma_{f} \gamma_{\beta}}\right]\right)
$$

Where:

$$
\begin{aligned}
& \lambda_{2}=\left[1.20-0.05\left(\xi_{0,-1} \sqrt{R_{c} / H_{m 0}}\right)\right] \\
& \lambda_{3}=\left[1.0+2.0 \exp \left(-35 R_{c} / h\right)\right]
\end{aligned}
$$

$$
\lambda_{4}=\max \left[0.95 ;\left(0.85+0.13 G_{c} / H_{m 0}\right)\right]
$$

$\lambda_{5}=\left(0.85+0.15 A_{c} / R_{c}\right)$

$\lambda_{6}=\left\{\begin{array}{cc}\max \left[1 ;\left(1.2-0.5 R_{c} / h\right)\right] & \text { if } B_{t}>0 \\ 1 & \text { if } B_{t}=0\end{array}\right.$

$\gamma_{\beta}=\left\{\begin{array}{ll}1-0.0077|\beta| & \text { for long }- \text { crested waves } \\ 1-0.0058|\beta| & \text { for short }- \text { crested waves }\end{array}\right.$ valid for $\beta \leq 60$ o

where $\xi_{0,-1}=\tan \alpha /\left[2 \pi H_{m 0} / g T_{-1,0}^{2}\right]^{1 / 2}$ is the Iribarren number corresponding to $\mathrm{T}_{-1,0}=\mathrm{m}$. $1 / m_{0}, \beta$ is the angle of wave attack, and $R_{c}, A_{c}, G_{c}, h, B_{t}$ are defined in Fig. 1.

Molines and Medina [17] pointed out that the roughness factor absorbs the information not taken by the explanatory variables; a methodology to calibrate the roughness factor was proposed given a specific overtopping estimator and database. The roughness factors were calibrated for the formulas given by Eq. (1), Eqs. (3) to (5) and the CLASH Neural Network. In this study, these overtopping estimators are used with the optimum roughness factors calculated by Molines and Medina [17]. Eq. (6) is applied here using the optimum roughness factors calculated by Molines and Medina [16]. 
Table 1 describes the explanatory variables used in Eqs. (1) to (6). Eq. (1) considers only 4 variables while Van Gent et al. [6] consider 11 variables; in all cases, the influence of $R_{c}$ and $H_{m 0}$ on wave overtopping is clear.

\begin{tabular}{l|ccccccccccccc}
\hline \multicolumn{1}{l}{$\begin{array}{l}\text { Overtopping } \\
\text { estimator }\end{array}$} & $\mathrm{R}_{\mathrm{c}}$ & $\mathrm{A}_{\mathrm{c}}$ & $\mathrm{G}_{\mathrm{c}}$ & $\mathrm{h}$ & $\mathrm{h}_{\mathrm{t}}$ & $\mathrm{B}_{\mathrm{t}}$ & $\cot \alpha$ & $\gamma_{\mathrm{f}}$ & $\mathrm{H}_{\mathrm{m} 0}$ & $\mathrm{~T}_{\mathrm{m}}$ & $\mathrm{T}_{\mathrm{p}}$ & $\beta$ \\
\hline Eq. (1) & $\mathrm{X}$ & & & & & & & $\mathrm{X}$ & $\mathrm{X}$ & & & $\mathrm{X}$ \\
\hline Eq. (2) & $\mathrm{X}$ & $\mathrm{X}$ & $\mathrm{X}$ & & & & $\mathrm{X}$ & & $\mathrm{X}$ & $\mathrm{X}$ & & \\
\hline Eq. (3) & $\mathrm{X}$ & & $\mathrm{X}$ & & & & & $\mathrm{X}$ & $\mathrm{X}$ & & & $\mathrm{X}$ \\
\hline Eq. (4) & $\mathrm{X}$ & $\mathrm{X}$ & & & & & $\mathrm{X}$ & $\mathrm{X}$ & $\mathrm{X}$ & & $\mathrm{X}$ & \\
\hline Eq. (5) & $\mathrm{X}$ & & & & & & & $\mathrm{X}$ & $\mathrm{X}$ & & & $\mathrm{X}$ \\
\hline Eq. (6) & $\mathrm{X}$ & $\mathrm{X}$ & $\mathrm{X}$ & $\mathrm{X}$ & & & $\mathrm{X}$ & $\mathrm{X}$ & $\mathrm{X}$ & $\mathrm{X}$ & & $\mathrm{X}$ \\
\hline CLASHNN & $\mathrm{X}$ & $\mathrm{X}$ & $\mathrm{X}$ & $\mathrm{X}$ & $\mathrm{X}$ & $\mathrm{X}$ & $\mathrm{X}$ & $\mathrm{X}$ & $\mathrm{X}$ & $\mathrm{X}$ & & $\mathrm{X}$ \\
\hline
\end{tabular}

Table 1. Explanatory variables to estimate wave overtopping rates. CLASHNN identifies the CLASH Neural Network (see Van Gent et al. [6]).

\subsection{Wave forces on crown walls}

Several prediction methods are given in the literature to calculate wave forces on crown walls, usually associated with a $0.1 \%$ probability of exceedance (see Negro et al. [18]); however, these methods show significant discrepancies (see Molines [19] and Negro et al. [5]).

USACE [20] described the methods reported by Jensen [21] and Pedersen [2] to evaluate wave forces on crown walls. The formula of Jensen [21] given by Eq. (8) is easy to apply but depends on calibrating two coefficients $\left(A_{1}\right.$ and $\left.A_{2}\right)$.

$F h_{0.1 \%}=\left(A_{1}+A_{2} \frac{\mathrm{H}_{s}}{A_{c}}\right) \rho g C_{h} L_{0 p}$

where $\mathrm{Fh}_{0.1 \%}$ is the horizontal wave force exceeded by $0.1 \%$ of the waves, $\mathrm{H}_{\mathrm{s}}$ is the significant wave height at the toe, $A_{c}$ is defined in Fig. $1, \rho$ is the water mass density, $g$ is the gravity acceleration, $C_{h}$ is the crown wall height, $L_{o p}$ is the deepwater wavelength 
associated to $T_{p}$ and $A_{1}, A_{2}$ are fitted coefficients which depend on the armor slope, wave obliquity, core permeability and crown geometry.

Pedersen [2] conducted small-scale 2D tests to analyze wave loads on crown walls caused by irregular non-breaking waves. He tested double-layer randomly-placed rock and Dolos armors as well as double-layer flat- and randomly-placed cube armors. According to Pedersen [2] the type of armor did not significantly influence wave forces on crown walls. A conventional cross section similar to that depicted in Fig. 1 was tested with tests charactersitics: $1.1<\xi_{0 m}=\tan \alpha /\left[2 \pi \mathrm{H}_{\mathrm{m} 0} / \mathrm{gT}^{2}\right]^{1 / 2}<4.2 ; 0.5<H_{s} / A_{c}<1.5$; $1<R_{c} / A_{c}<2.6 ; 0.3<A_{c} / G_{c}<1.1$ and $1.5<\cot \alpha<3.5$. Fig. 2 and Eq. (9) describe the formula given by Pedersen [2] to calculate wave forces on the crown wall. The wave virtual runup was estimated using Eq. (9g) given by Van der Meer and Stam [22]; the use of other virtual run-up formulas would lead to different fitted coefficients.

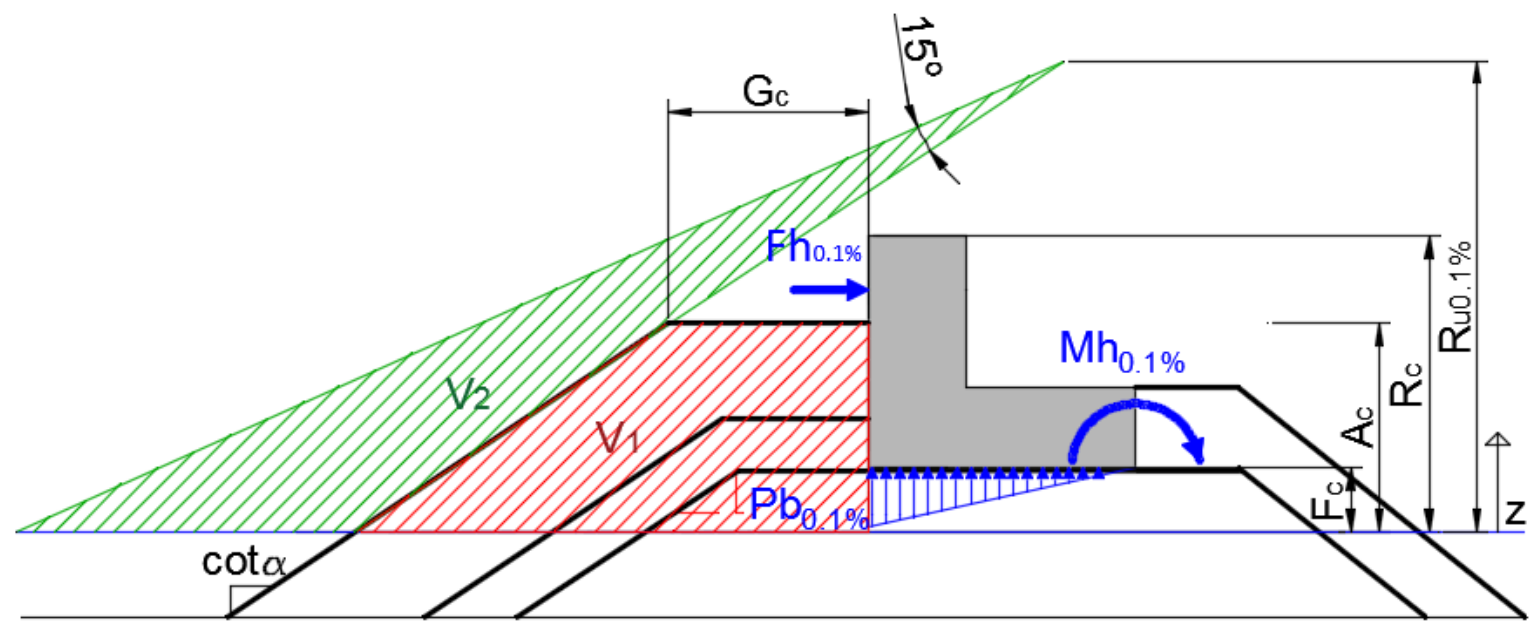

Fig. 2. Variables used by Pedersen [2].

$$
\begin{aligned}
& F h_{0.1 \%}=0.21 \sqrt{\frac{L_{0 m}}{G_{c}}}\left(p_{m} \cdot y_{e f f} \cdot 1.6+\frac{p_{m}}{2} V\left(A_{c}-F_{c}\right)\right) \\
& M h_{0.1 \%}=0.55\left(\left(A_{c}-F_{c}\right)+y_{e f f}\right) F h_{0.1 \%} \\
& P b_{0.1 \%}=1.00 V p_{m}
\end{aligned}
$$

where: 
$p_{m}=\rho g\left(R_{u 0.1 \%}-A_{c}\right)$

$V=\left\{\begin{array}{l}V_{2} / V_{1} \text { for } V_{2}<V_{1} \\ 1 \quad \text { for } V_{2} \geq V_{1}\end{array}\right.$

$y_{\text {eff }}=\min \left(0.5 * \frac{R_{u 0.1 \%}-A_{c}}{\sin \alpha} \frac{\sin 15^{\circ}}{\cos \left(\alpha-15^{\circ}\right)} ;\left(R_{c}-A_{c}\right)\right)$

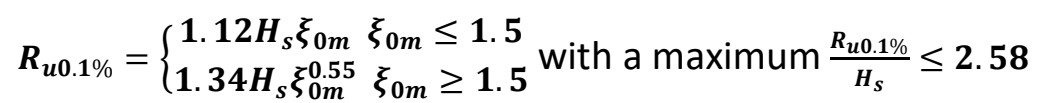

(9g)

where $\mathrm{Fh}_{0.1 \%}$ is the horizontal wave force exceeded by $0.1 \%$ of the waves, $\mathrm{Mh}_{0.1 \%}$ is the overturning moment generated by horizontal forces exceeded by $0.1 \%$ of the waves, $\mathrm{Pb}_{0.1 \%}$ is the up-lift pressure at the seaward corner of the crown wall base exceeded by $0.1 \%$ of the waves, $R_{u 0.1 \%}$ is the virtual wave run-up, $A_{c}, R_{c}, G_{c}$ are defined in Fig. $2, F_{c}$ is the foundation level, $\quad \mathrm{L}_{0 \mathrm{~m}}=\mathrm{gTm}^{2} /(2 \pi)$ is the deepwater wavelength, $\xi_{0 \mathrm{~m}}=\tan \alpha /\left[2 \pi H_{m 0} / g T_{m}\right]^{1 / 2}$ is the Iribarren number corresponding to mean period $\left(\mathrm{T}_{\mathrm{m}}\right)$ and $V_{1}$ and $V_{2}$ are two coefficients dependent on the cross-section geometry (see Fig. 2).

Martín et al. [4] proposed a method to calculate wave forces on crown walls for the case of regular waves using the virtual wave run-up estimations given by Losada and Giménez-Curto [23]. The method is applicable to those crown walls of mound breakwaters that are not affected by impulsive wave pressures, i.e. those in which the waves are broken or run up on the slope. The tested cross-section was a model of the Príncipe de Asturias Breakwater at the Port of Gijón (Spain) with 120- and 90-tonne cubes randomly-placed in the armor and core, respectively, which is a relatively permeable structure compared to conventional mound breakwaters. Martín et al. [4] introduced the influence of the type of armor through coefficients calibrated using the virtual run-up estimations. 
Nørgaard et al. [24] tested double-layer rock armored breakwaters and adapted Pedersen's formula [2] for shallow water conditions by modifying the virtual run-up term. Nørgaard et al. [24] also proposed using $\mathrm{H}_{0.1 \%}$ both in shallow and deep water conditions to represent the virtual run-up exceeded by $0.1 \%$ of the waves in Pedersen's formula. These authors proposed calculating Ru $\mathrm{u}_{0.1 \%}$ given by Eq. (9g) using $\mathrm{H}_{\mathrm{s}} / \mathrm{H}_{0.1 \%}=0.538$ given by the Rayleigh distribution rather than the measured $\mathrm{H}_{\mathrm{s}}$. Finally, Nørgaard et al. [24] proposed Eq. (10) to calculate wave forces on crown walls:

$$
\begin{aligned}
& \boldsymbol{F} \boldsymbol{h}_{\mathbf{0 . 1} \%}=\mathbf{0 . 2 1} \sqrt{\frac{L_{\mathbf{0 m}}}{G_{\boldsymbol{c}}}}\left(\boldsymbol{p}_{\boldsymbol{m}} \cdot \boldsymbol{y}_{\text {eff }} \cdot \mathbf{1 . 0 0 + \frac { p _ { m } } { 2 }} \boldsymbol{V}\left(\boldsymbol{A}_{\boldsymbol{c}}-\boldsymbol{F}_{\boldsymbol{c}}\right)\right) \\
& M h_{0.1 \%}=\left(\left(A_{c}-F_{c}\right)+\frac{1}{2} y_{\text {eff }} 0.40\right) 0.21 \sqrt{\frac{L_{0 m}}{G_{c}}}\left(p_{m} \cdot y_{\text {eff }} \cdot 1.00\right)+\frac{1}{2}\left(A_{c}-F_{c}\right) \frac{1}{2} 0.21 \sqrt{\frac{L_{0 m}}{G_{c}}}\left(p_{m} V\left(A_{c}-F_{c}\right)\right) 0.95 \\
& P b_{0.1 \%}=1.00 \mathrm{~V} p_{m}
\end{aligned}
$$

where $L_{0 m}, G_{c}, p_{m}, Y_{\text {eff, }} V, A_{c}, F_{c}$ are defined in Fig. 2 and Eq. (9). The range of application of this formula is $2.3<\xi_{0 m}<4.9 ; 0.5<H_{s} / A_{c}<1.63 ; 1<R_{c} / A_{c}<1.7$; $0.58<A_{c} / G_{c}<1.21 ; 0.19<\mathrm{H}_{\mathrm{mo}} / \mathrm{h}<0.55$ and $0.02<\mathrm{H}_{\mathrm{mo}} / \mathrm{L}_{0 \mathrm{~m}}<0.041$.

Recently, Molines [8] proposed Eq. (11) to estimate wave forces on crown walls. The horizontal force exceeded only by the highest $0.1 \%$ of the waves, $\mathrm{Fh}_{0.1 \%}$, and the maximum up-lift pressure generated by the wave that caused $\mathrm{Fh}_{0.1 \% \text {, hereafter }}$ $\mathrm{PbFh}_{0.1 \%}$, were estimated. Eq. (11) used the roughness factor $\left(\gamma_{\mathrm{f}}\right)$ to take into account the influence of the type of armor on wave forces on crown walls. 


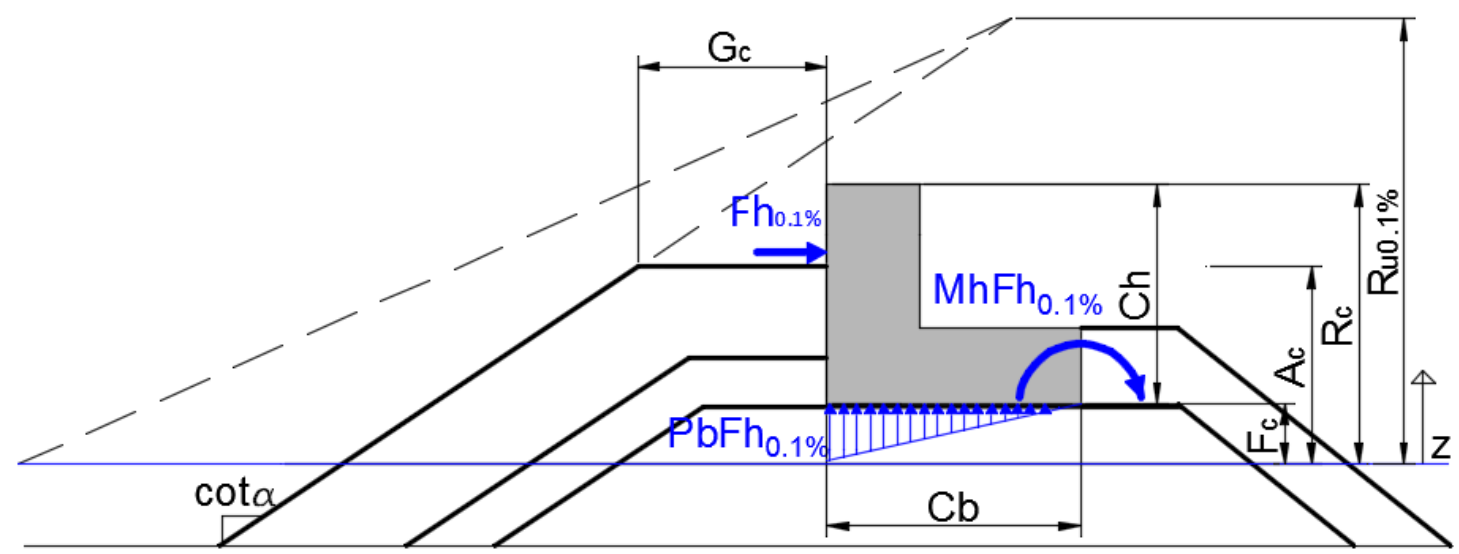

Fig. 3. Variables used by Molines [8].

Molines [8] proposed the use of Eq. (9b) given by Pedersen [2] to estimate the overturning moments due to horizontal forces, and a conventional triangular pressure distribution to estimate the overturning moments due to the up-lift forces.

$$
\begin{aligned}
& \frac{F h_{0.1 \%}}{\left(0.5 \rho g C_{h}^{2}\right)}=\left(-1.29+1.80 \frac{\gamma_{f} R_{u 0.1 \%}}{R_{c}}+0.93 \frac{\left(R_{c}-A_{c}\right)}{C_{h}}+0.16 \sqrt{\frac{L_{m}}{G_{c}}}\right)^{2} \\
& \frac{P b F h_{0.1}}{\left(0.5 \rho g C_{h}\right)}=\frac{1}{0.5}\left(-0.86+0.75 \frac{\gamma_{f} R_{u 0.1 \%}}{R_{c}}+0.41 \frac{\left(R_{c}-A_{c}\right)}{C_{h}}+0.17 \sqrt{\frac{L_{m}}{G_{c}}}-0.9 \frac{F_{c}}{C_{h}}\right)^{2}
\end{aligned}
$$

where $R_{u 0.1 \%}$ is the virtual wave run-up calculated using Eq. (9g) given by Van der Meer and Stam [21], $\gamma_{f}$ [cube, 2-layer] $=0.50 ; \gamma_{f}$ [Cubipod, 1-layer] $=0.46, \gamma_{f}$ [Cubipod, 2layer $]=0.44, \mathrm{~T}_{\mathrm{m}}=\mathrm{T}_{01}=\mathrm{m}_{0} / \mathrm{m}_{1}$ is the mean wave period, $\left.\xi_{0 m}=\tan \alpha / \sqrt{2 \pi H_{s} /\left(g T_{m}{ }^{2}\right)}\right)$, $L_{m}=\frac{g T_{m}^{2}}{2 \pi} \tanh \left(\frac{2 \pi h}{L_{m}}\right)$ and $\mathrm{R}_{c}, \mathrm{~A}_{\mathrm{c}}, \mathrm{G}_{\mathrm{c}}, \mathrm{F}_{\mathrm{c}}, \mathrm{C}_{\mathrm{h}}, \mathrm{C}_{\mathrm{b}}$ are defined in Fig. 3.

Hereafter, the following notations are used:

- $\mathrm{Fh}=\mathrm{Fh}_{0.1 \%} /\left(0.5 \rho g \mathrm{C}_{\mathrm{h}}{ }^{2}\right)$ is the dimensionless horizontal force exceeded by $0.1 \%$ of the waves.

$-\mathrm{Pb}=\mathrm{Pb}_{0.1 \%} /\left(0.5 \rho g \mathrm{C}_{h}\right)$ is the dimensionless up-lift pressure exceeded by $0.1 \%$ of the waves.

- $\mathrm{PbF}=\mathrm{PbFh}_{0.1 \%} /\left(0.5 \rho g \mathrm{C}_{h}\right)$ is the dimensionless up-lift pressure simultaneous with $\mathrm{Fh}_{0.1 \%}$. 
- $\mathrm{Mh}=\mathrm{Mh}_{0.1 \%} /\left(\rho \mathrm{gCh}^{3}\right)$ is the dimensionless overturning moment due to horizontal forces exceeded by $0.1 \%$ of the waves.

- MhF=MhFho.1\%/ $\left(\rho g \mathrm{Ch}^{3}\right)$ is the dimensionless overturning moment due to horizontal forces simultaneous with $\mathrm{Fh}_{0.1 \%}$.

$\mathrm{Mh}_{0.1 \%}$ and $\mathrm{Pb}_{0.1 \%}$ may not necessarily be caused by the same wave as $\mathrm{Fh}_{0.1 \%}$ whereas $\mathrm{PbFh}_{0.1 \%}$ and $\mathrm{MhFh}_{0.1 \%}$ are generated by the same wave as $\mathrm{Fh}_{0.1 \%}$.

For single-peaked wave energy spectra with a spectral shape similar to JONSWAP spectra, $\mathrm{T}_{\mathrm{p}} \approx 1.2 \mathrm{~T}_{\mathrm{m}}$. Assuming a Gaussian error distribution $\mathrm{N}\left(\mu, \sigma^{2}\right)$, the reliability of Eq. (11a) and Eq. (11b) was given by $\mathrm{N}\left(\mathrm{Fh}, 0.28^{2}\right)$ and $\mathrm{N}\left(\mathrm{PbF}, 0.085^{2}\right)$, respectively. The ranges of application of Eq. (11) are $0.355<\frac{\gamma_{f} R_{u 0.1 \%}}{R_{c}}<0.938,0.067<\frac{\left(R_{c}-A_{c}\right)}{C_{h}}<0.589$, $3.134<\sqrt{\frac{L_{m}}{G_{c}}}<6.539$ and $0.013<\frac{F_{c}}{C_{h}}<0.267$.

Pedersen [2], Martín et al. [4] and Nørgaard et al. [24] assumed pressure continuity between the horizontal pressure at the lowest point of the frontal vertical wall and the vertical pressure at the seaward corner of the crown wall base. Pedersen [2] and Nørgaard et al. [24] estimated the maximum up-lift forces using the horizontal pressure at the lowest point of the vertical wall exceeded by $0.1 \%$ of the waves, which may not necessarily happen at the same time as the horizontal force exceeded by $0.1 \%$ of the waves. Molines [8] noticed that overestimations up to three times are possible when comparing the calculated up-lift force assuming pressure continuity with the measured up-lift force from small-scale $2 \mathrm{D}$ tests. It is convenient to point out that the foundation level $\left(F_{c}\right)$ has a relevant impact on the up-lift forces: the higher the foundation level, the lower the up-lift forces. 
Table 2 summarizes the explanatory variables used in Eqs. (9) to (11). Eqs. (9) and (10) consider eight variables while Eq. (11) considers ten variables; in all cases, the influence of $R_{c}, A_{c}, G_{c}, C_{h}, C_{b}$, cota, $H_{m 0}$ and $T_{m}$ on wave forces on crown walls is clear. Explanatory variables listed in Table 2 are similar to those in Table 1 to estimate mean wave overtopping discharges.

\begin{tabular}{|c|c|c|c|c|c|c|c|c|c|c|}
\hline \multirow{2}{*}{$\begin{array}{l}\text { Wave force } \\
\text { estimator }\end{array}$} & \multicolumn{10}{|c|}{ Explanatory variables } \\
\hline & $\mathrm{R}_{\mathrm{c}}$ & $A_{c}$ & $\mathrm{G}_{\mathrm{c}}$ & $\mathrm{F}_{\mathrm{c}}$ & $C_{h}$ & $\mathrm{C}_{\mathrm{b}}$ & $\cot \alpha$ & $\gamma_{f}$ & $\mathrm{H}_{\mathrm{m} 0}$ & $\mathrm{~T}_{\mathrm{m}}$ \\
\hline Eq. (9) & $x$ & $x$ & $x$ & & $\mathrm{X}$ & $\mathrm{X}$ & $x$ & & $x$ & $\mathrm{X}$ \\
\hline Eq. (10) & $x$ & $x$ & $x$ & & $x$ & $x$ & $x$ & & $x$ & $x$ \\
\hline Eq. (11) & $x$ & $x$ & $x$ & $x$ & $x$ & $x$ & $x$ & $\mathrm{x}$ & $x$ & $x$ \\
\hline
\end{tabular}

Table 2. Explanatory variables to estimate wave forces on crown walls.

Each wave causes a maximum horizontal wave force on the crown wall which is not simultaneous with the maximum up-lift force and overturning moments. Furthermore, the wave causing the maximum horizontal force on the crown wall may not be the same wave causing the maximum up-lift pressure or overturning moment. Eqs. (9) and (10), based on the methodology followed by Pedersen [2], provide the extreme forces and overturning moments exceeded by $0.1 \%$ of the waves to be considered for the design, regardless of the simultaneity of events. Eq. (11), based on the methodology of Molines [8], provides the extreme horizontal wave force exceeded by $0.1 \%$ of the waves and the corresponding maximum up-lift pressure and overturning moment generated by the same wave.

\section{Explanatory variables affecting wave forces on crown walls}

In this study, seven dimensionless variables were considered as candidate explanatory variables which may influence wave forces on crown walls: 
1. $X_{1}=R_{c} /\left(\gamma_{f} H_{m 0}\right)$ is the corrected dimensionless crown wall freeboard; it is the most common and widely accepted dimensionless variable estimating overtopping discharges (see Eqs. 1 to 6). The effect of armor roughness is taken into account using the roughness factor $\left(\gamma_{f}\right)$. The higher the $\gamma_{f}$, the higher the virtual run-up and overtopping rates.

2. $X_{2}=\xi_{0 p}=\tan \alpha /\left[2 \pi H_{m o} / g T_{p}^{2}\right]^{1 / 2}$ is Iribarren's number or the breaker parameter; it determines the type of wave breaking on the slope. The influence of Iribarren's number on the virtual run-up estimation and forces on crown walls is clearly described in Pedersen [2], Nørgaard et al. [24] and Molines [8].

3. $X_{3}=\gamma_{f} R_{u 0.1 \%} / R_{c}$ is the corrected relative virtual wave run-up; virtual wave run-up is widely used in the literature (see Eqs. 9 to 11) to estimate wave forces on crown walls. In this study, Eq. (9g) is considered.

4. $X_{4}=\left(R_{c}-A_{c}\right) / C_{h}$ is the wall protection ratio; it is widely accepted that forces on the wall section protected by the armor are lower than forces on the unprotected wall. When $\mathrm{X}_{4}=0, R_{c}=A_{c}$, the crown wall is completely protected by the armor.

5. $X_{5}=\sqrt{L_{m} / G_{c}}$ is the relative crest berm width; this includes the effect of crest berm width. It is clear that wider crest berms lead to lower wave overtopping rates and lower forces on the crown wall.

6. $X_{6}=F_{c} / L_{O p}$ is the relative foundation elevation; the ratio between the foundation elevation of the crown wall and the deepwater wave length, $X_{6}$, is similar to that used in Eq. (11). A higher relative foundation elevation reduces forces on 
the crown wall. Therefore, the ratio between $F_{c}$ and $L_{o p}$ may significantly influence the up-lift forces.

7. $X_{7}=\log Q=\log \left(q / \sqrt{g H_{m 0}^{3}}\right)$ is the dimensionless measured mean wave overtopping rate; this is a variable widely used in the literature to linearize the measured dimensionless mean overtopping rate, and it is closely related to virtual wave run-up.

$X_{7}$ not only is dependent on $X_{1}$ to $X_{6}$, but it is also a variable related to other structural characteristics (filter and core permeability, etc.) affecting virtual run-up and forces on crown walls. $X_{7}$ is the only variable that may take into consideration the structural response of the breakwater in physical model tests, whereas $X_{1}$ to $X_{6}$ are climatic or geometric variables which do not consider the breakwater performance. Fig. 4 shows a scheme of the dependency of wave overtopping and wave forces on crown walls, on selected explanatory variables $\left(X_{1}\right.$ to $\left.X_{6}\right)$ and on other explanatory variables $\left(X_{8}\right.$ to $\left.X_{n}\right)$ such as core and filter permeability. $X_{7}=\log Q$ is relatively easy to measure in small-scale tests and may be used to estimate wave forces on crown walls. 


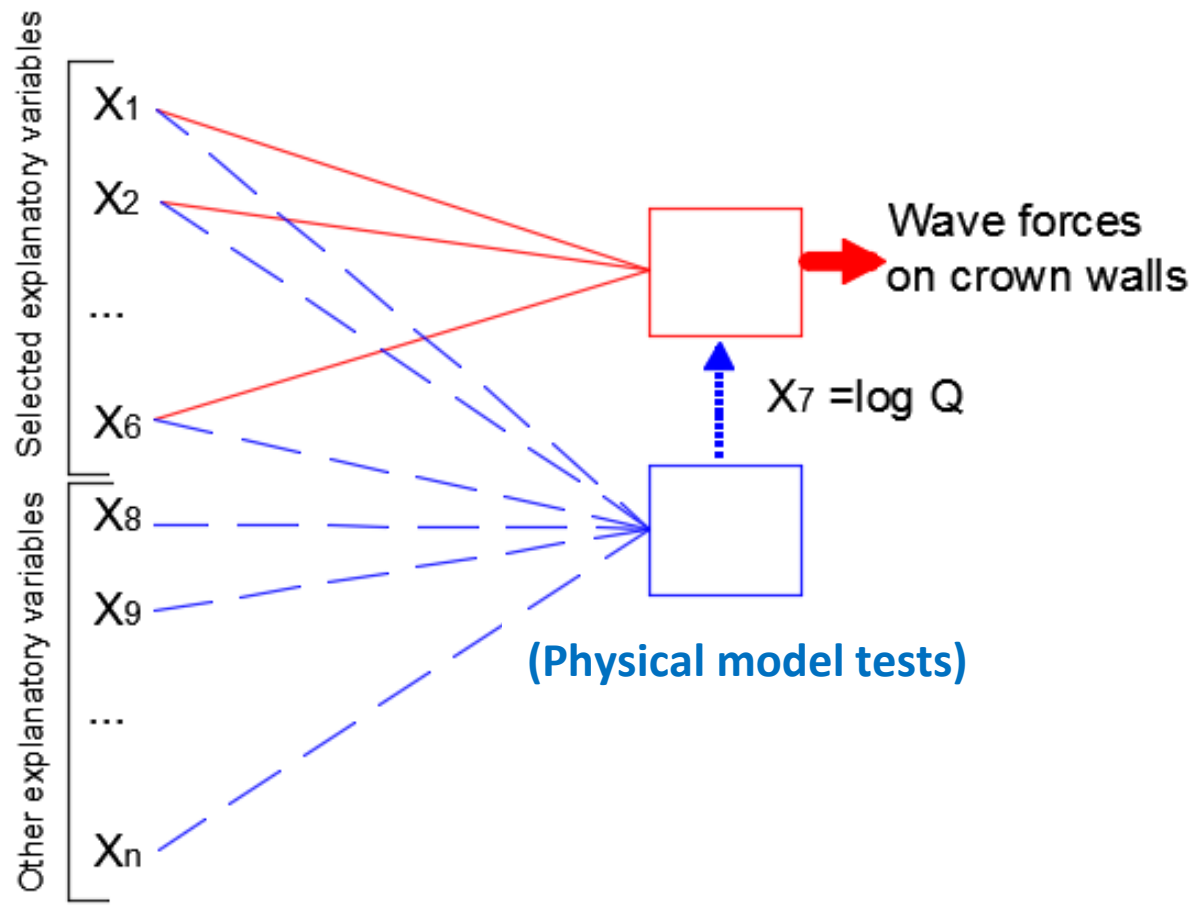

Fig. 4. Scheme of estimation of wave forces on crown walls.

\section{Database of wave forces on crown walls}

111 experimental tests with $\mathrm{Q}=\mathrm{q} /\left(\mathrm{gH}_{\mathrm{m} 0^{3}}\right)^{0.5}>10^{-6}$ and $\mathrm{F}_{\mathrm{c}}[\mathrm{m}] \geq 0$ used by Pedersen [2] and 163 experimental tests used by Molines [8] are considered in this study to analyze the relationship between the candidate explanatory variables detailed in Section 3 and the dimensionless horizontal, up-lift forces, and overturning moments. Table 3 provides the ranges of the candidate variables of Pedersen [2] and Molines [8] tests.

\begin{tabular}{lcc}
\hline Variable & Pedersen [2] tests: 111 & Molines [8] tests: 163 \\
\cline { 2 - 3 } & {$[$ Min., Max.] } & {$[$ Min., Max.] } \\
\hline$R_{c} /\left(\gamma_{f} H_{m 0}\right)$ & {$[1.671,5.555]$} & {$[2.634,6.547]$} \\
\hline$\xi_{0 p}$ & {$[1.386,5.744]$} & {$[2.645,7.766]$} \\
\hline$\gamma_{f} R_{u 0.1 \%} / R_{c}$ & {$[0.438,1.410]$} & {$[0.355,0.938]$} \\
\hline$\left(R_{c}-A_{c} / C_{h}\right.$ & {$[0.000,0.545]$} & {$[0.067,0.589]$} \\
\hline$\sqrt{L_{m} / G_{c}}$ & {$[2.638,4.551]$} & {$[3.399,6.539]$} \\
\hline$F_{c} / L_{o p}$ & {$[0.000,0.013]$} & {$[0.000,0.030]$} \\
\hline $\log Q$ & {$[(-5.611),(-2.786)]$} & {$[(-6.000),(-2.956)]$} \\
\hline
\end{tabular}

Table 3. Pedersen [2] and Molines [8] datasets. 
The relative Mean Squared Error (rMSE) given by Eq. (12) is used here to measure the goodness of fit of the estimator " $\mathrm{e}$ " when applied to target or observed data "o" ( $\mathrm{i}=$ $1,2, \ldots, N)$. rMSE is the proportion of variance not explained by the estimator " $e$ ". The lower the rMSE, the better.

$$
\operatorname{rMSE}_{e}(Y o)=\frac{\operatorname{MSE}_{e}(Y o)}{\operatorname{Var}(Y o)}=\frac{\sum_{i=1}^{N}\left(Y e_{i}-Y o_{i}\right)^{2}}{N \cdot \operatorname{Var}(Y o)}
$$

where " $e$ " refers to the estimator; $Y e$ and $Y o$ are the estimated and target dimensionless output variables, respectively; $N$ is the total number of data and $i$ is the data index $(i=1,2, \ldots, N)$.

Fig. 5 illustrates the performance of estimations given by Eqs. (9) and (11) to Pedersen [2] and Molines [8] data within their application ranges. 

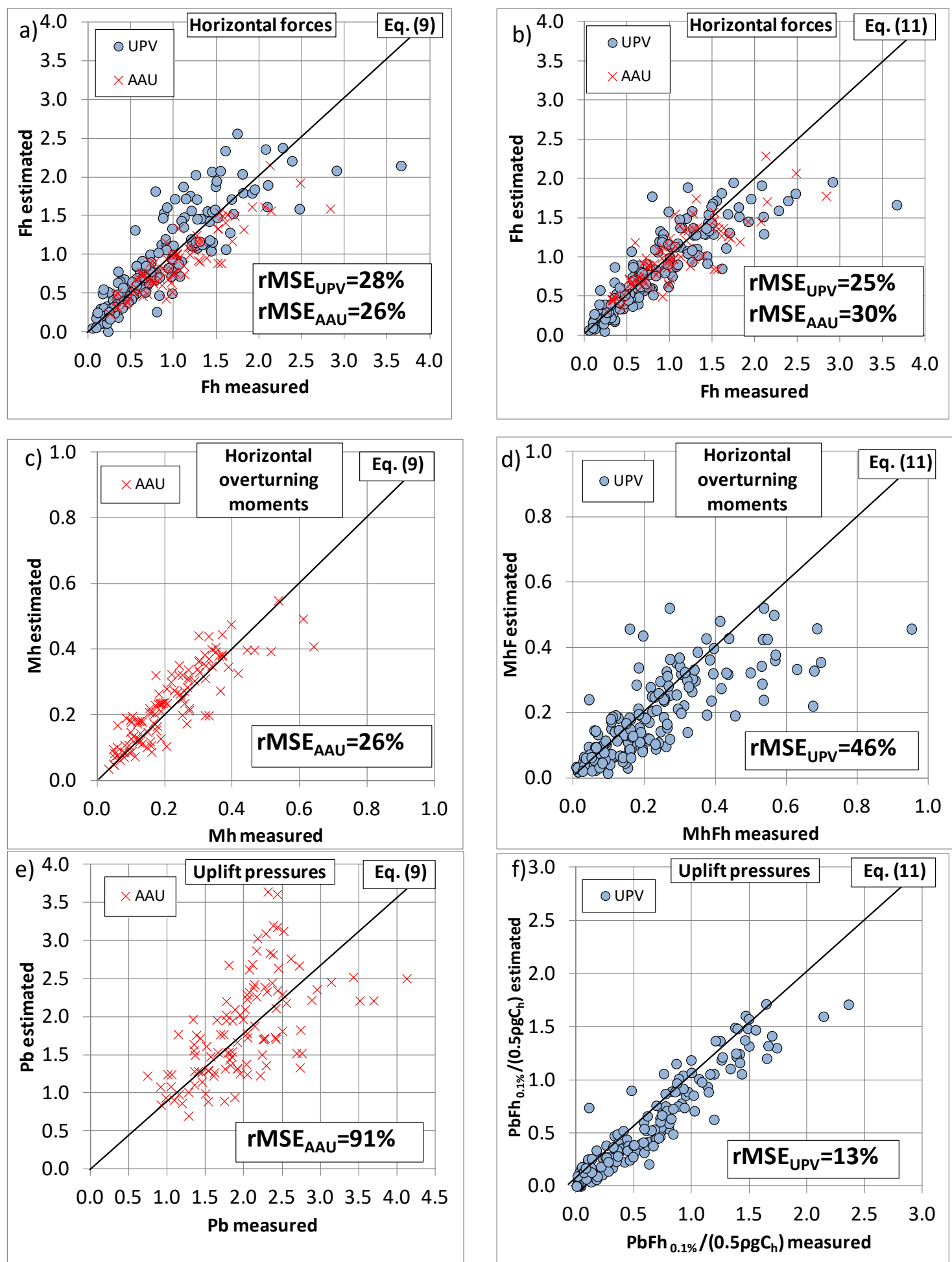

Fig. 5. Comparison between measured and estimated dimensionless horizontal forces ( $a$ and $b$ ), overturning moments ( $c$ and $d$ ) and up-lift pressures( $e$ and $f$ ) on crown walls for Eqs. (9) and (11). Pedersen's [2] dataset is referred to as AAU and Molines' [8] dataset is referred to as UPV. 


\section{Methodology to develop the new formulas}

A neural network (NN) is a multiparametric model which is able to capture complex nonlinear relationships between input explanatory variables and output variables (wave forces and moments on crown walls). Although a NN is a "black-box" and it is not easy to see any clear relationship between input and output variables, it is relatively easy (see Garrido and Medina [25] and Molines and Medina [16]) to find conventional explicit relationships between input and output variables when using the NN as a simulator. In this study, NN models are used to detect relationships between input and output variables to develop new formulas to estimate wave forces and overturning moments on crown walls.

\subsection{General outline}

Given the Pedersen [2] and Molines [8] datasets described in Section 4 and the seven candidate explanatory variables $\left(X_{1}\right.$ to $\left.X_{7}\right)$ described in Section 3 , a NN structure was considered with one input layer up to seven neurons $\left(\mathrm{N}_{\mathrm{i}}=1\right.$ to 7$)$, one hidden layer with seven neurons $\left(N_{h}=7\right)$ and one output neuron $\left(N_{0}=1\right)$ (see Fig. 6). The NN structures were referred to as $\mathrm{IN}_{\mathrm{i}} \mathrm{HN}_{\mathrm{h}} \mathrm{ON}$. Each NN was trained using the Early Stopping criterion to prevent overlearning (see $\operatorname{MATLAB}^{\circledR}[26]$ ). $70 \%, 15 \%$ and $15 \%$ of the data were randomly selected for training, validating and testing, respectively. The number of free parameters of each $\mathrm{NN}$ model is given by $\mathrm{P}=\mathrm{N}_{\circ}+\mathrm{N}_{h}\left(\mathrm{~N}_{i}+\mathrm{N}_{\circ}+1\right)$; Table 4 shows the number of training data $(T)$ and the number of free parameters $(P)$ corresponding to the wave forces and overturning moments on the crown wall. Overlearning is likely to occur when $\mathrm{P} / \mathrm{T} \geq 1$; the Early Stopping criterion leads to rapid interruption of the 
training process in those cases. The number of neurons in the hidden layer was $\mathrm{N}_{h}=7$ to keep $\mathrm{P} / \mathrm{T}<1$ in the worst case (I7H7O1).

\begin{tabular}{|c|c|c|c|}
\hline & $\mathrm{Fh}_{0.1 \%}$ & $\mathrm{~Pb}_{0.1 \%}, \mathrm{Mh}_{0.1 \%}$ & $\mathrm{PbFh}_{0.1 \%}, \mathrm{MhFh}_{0.1 \%}$ \\
\hline N (\# data) & 274 & 111 & 163 \\
\hline $\mathrm{T}$ (\# training data) & 192 & 78 & 115 \\
\hline $\mathrm{N}_{\mathrm{i}}$ (\# input neurons) & & 1 to 7 & \\
\hline $\mathrm{N}_{\mathrm{h}}$ (\# hidden neurons) & & 7 & \\
\hline $\mathrm{N}_{\mathrm{o}}$ (\# output neurons) & & 1 & \\
\hline P (\# parameters) & & 22 to 64 & \\
\hline $\mathrm{P} / \mathrm{T}$ & $11 \%$ to $33 \%$ & $28 \%$ to $82 \%$ & $19 \%$ to $56 \%$ \\
\hline
\end{tabular}

Table 4. Number of data and number of parameters for each wave force.

First, the process of ranking the relevance of each input variable started by selecting the $11 \mathrm{H} 701$ structure, with one single input variable. A NN model was trained for each one of the candidate variables $\left(X_{1}\right.$ to $\left.X_{7}\right)$ used as a single input variable. The input variable associated with the $11 \mathrm{H} 701$ model with the minimum $\mathrm{rMSE}_{11 \mathrm{H} 701}$ (test data) was the most relevant explanatory variable. However, the $N N$ training result was dependent on the data selected for training, validating and testing. In order to overcome the uncertainty associated to data selection, 1000 random resamples of the initial dataset were generated. The candidate variable $X_{j}$ that showed the lowest $\mathrm{rMSE}_{11 \mathrm{H701}}$ (test data) in most of the 1000 resamples was selected as the best explanatory variable. The uncertainty in selecting $X_{j}$ was described by the $5 \%, 50 \%$ and 95\% percentiles of $\mathrm{rMSE}_{11 \mathrm{H} 701}$ (test data).

Second, the $12 \mathrm{H} 7 \mathrm{O} 1$ structure was considered for the NN model, fixing one input neuron with the first selected variable $X_{j}$ and varying the second input with each candidate variable not previously selected $\left(X_{1} \ldots . X_{j-1}, X_{j+1} \ldots . X_{7}\right)$. The second input variable associated with the $12 \mathrm{H} 7 \mathrm{O} 1$ model with the minimum $\mathrm{rMSE}_{12 \mathrm{H} 701}$ (test data) was the 
second most relevant explanatory variable. This method was repeated with $13 \mathrm{H} 701$, $14 \mathrm{H} 7 \mathrm{O} 1$, etc. The process finished when all the candidate variables were included in the final $17 \mathrm{H} 701 \mathrm{NN}$. The order of selecting the input variables indicated the ranking of relevance of explanatory variables. Fig. 6 shows the NN structures I1H7O1 and I2H7O1.

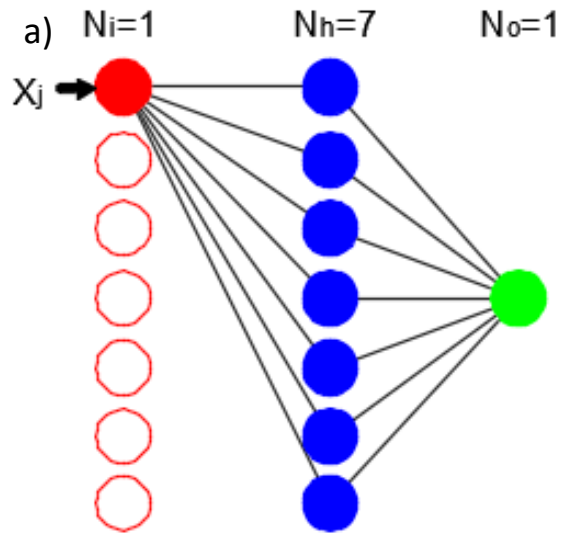

I1H701

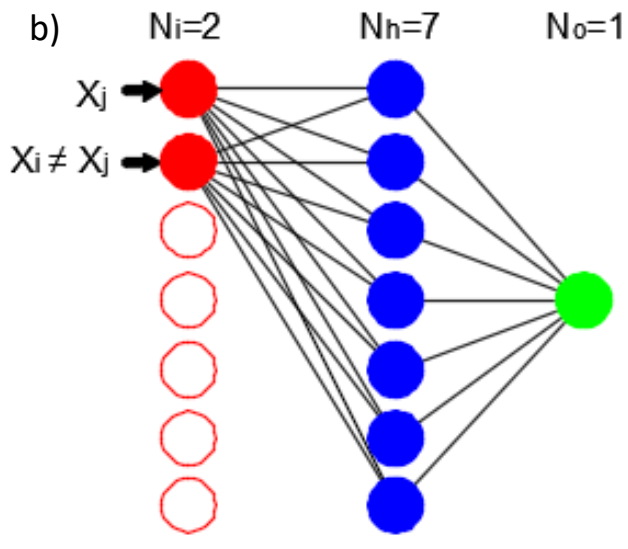

12H701

Fig. 6. Two NN structures: a) I1H7O1 and b) I2H7O1.

When the explanatory variables were ranked, simulations were conducted with the NN models to develop new estimators of wave forces on the crown wall. The flow-chart in Fig. 7 summarizes the methodology used for this study. 


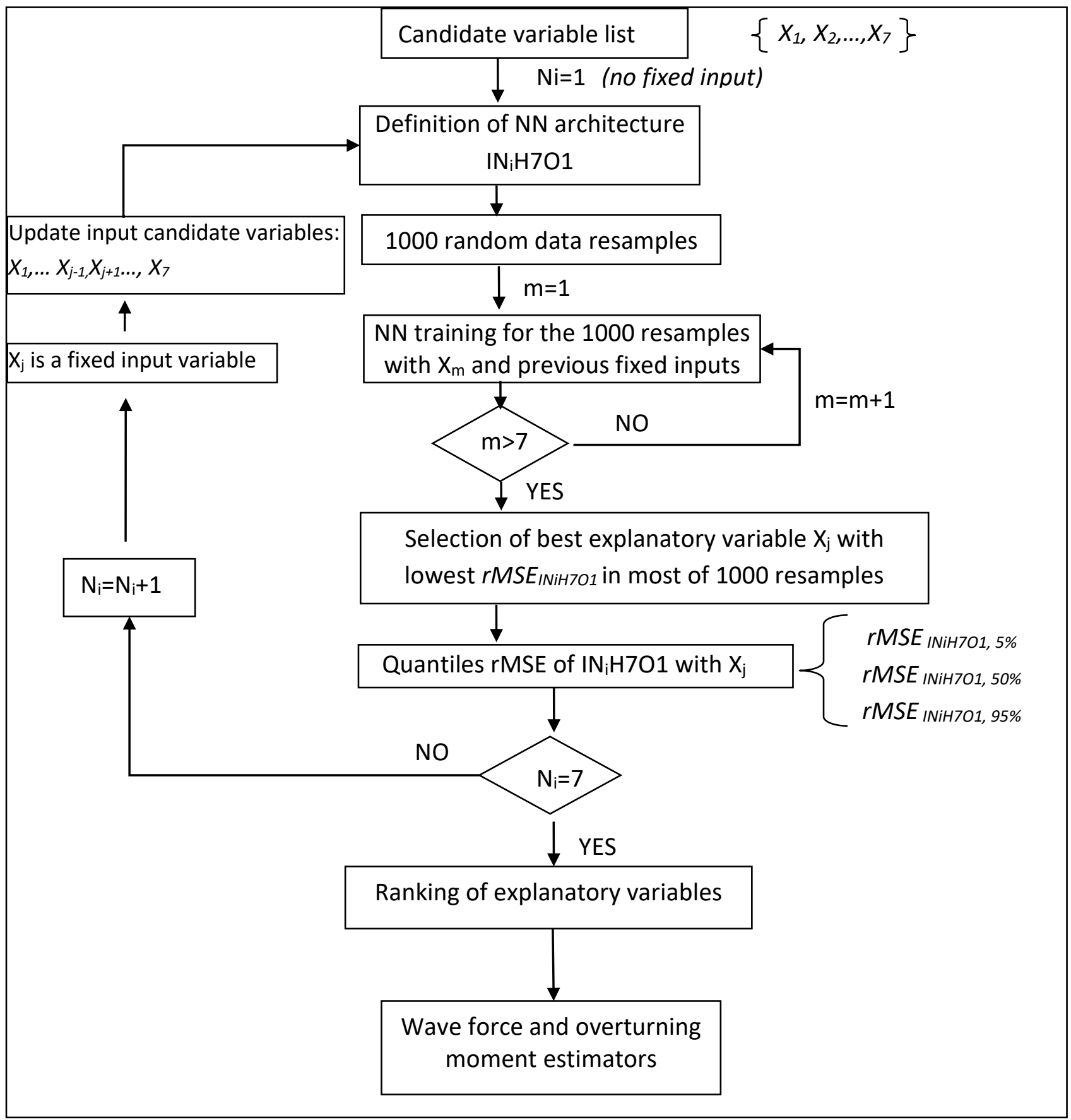

Fig. 7. Flow-chart to develop the NN models to estimate wave forces on the crown wall.

\subsection{Estimation of horizontal wave force: $F h=F h_{0.1 \%} /\left(0.5 \rho g C_{h}{ }^{2}\right)$.}

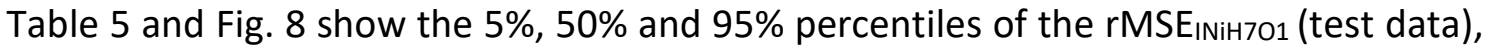
the $90 \%$ confidence interval (CI) of the $\mathrm{rMSE}_{\text {INiH701 }}$ (test data), and the rMSE 
corresponding to Eqs. (9) and (11) with solid and dotted red lines, respectively. The variable $X_{7}=\log Q$ was selected first as the most relevant variable in $96 \%$ of the cases; $\log Q$ explained approximately $59 \%$ of the variance of the dimensionless horizontal wave forces, Fh. $X_{2}=\xi_{0 p}, X_{4}=\left(R_{c}-A_{c}\right) / C_{h}$ and $X_{1}=R_{d} /\left(\gamma_{f} H_{m 0}\right)$ were significant additional explanatory variables which explained an additional $20 \%$ of the variance of Fh.

Number of input variables $(\mathrm{Ni})$ in the $\mathrm{IN}_{\mathrm{i}} \mathrm{H} 7 \mathrm{O} 1$ model

\begin{tabular}{lccccc}
\cline { 2 - 6 } & & 1 & 2 & 3 & 4 \\
\hline Selected variable $\left(\mathrm{X}_{\mathrm{j}}\right)$ & & $\mathrm{X}_{7}=\log \mathrm{O}$ & $\mathrm{X}_{2}=\xi_{0 \mathrm{p}}$ & $\mathrm{X}_{4}=\left(R_{c}-A_{c}\right) / C_{h}$ & $\mathrm{X}_{1}=R_{c} /\left(\gamma_{\mathrm{f}} H_{m 0}\right)$ \\
\hline \multirow{3}{*}{ rMSE $_{\text {INiH701 (test data) }}$} & $5 \%$ & $27.5 \%$ & $20.3 \%$ & $14.4 \%$ & $11.9 \%$ \\
\cline { 2 - 6 } & $50 \%$ & $40.8 \%$ & $30.7 \%$ & $24.8 \%$ & $19.8 \%$ \\
\cline { 2 - 6 } & $95 \%$ & $56.3 \%$ & $47.4 \%$ & $41.5 \%$ & $40.4 \%$ \\
\hline
\end{tabular}

Table 5. Ranking of the relevant variables affecting dimensionless horizontal wave force, Fh.

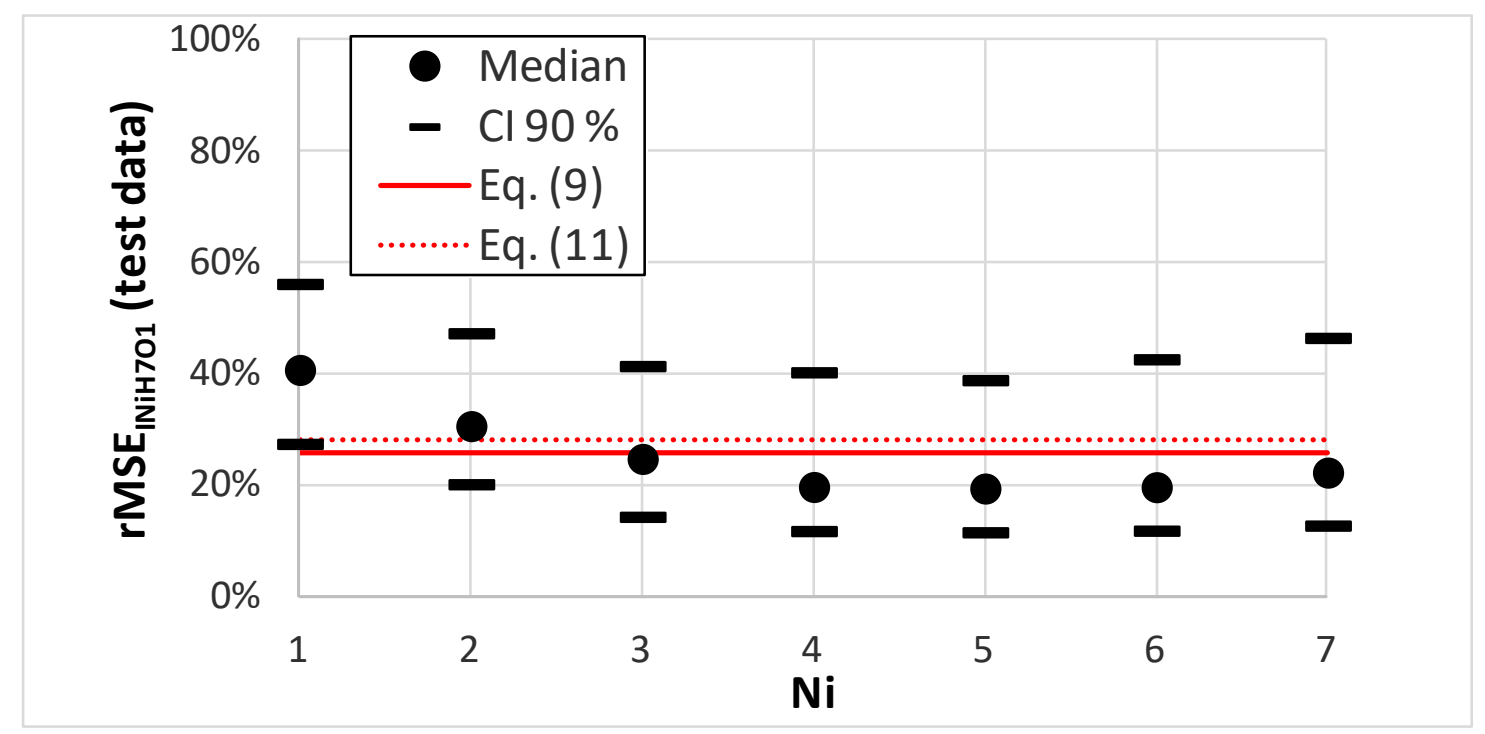

Fig. 8. Influence of the number of input variables (Ni) on the rMSE of Fh.

Analyzing Pedersen [2] and Molines [8] experimental data, Fig. 9a shows the predictions of the $11 \mathrm{H} 701$ model as function of $\mathrm{X}_{7}=\log \mathrm{Q}$, where an approximate linear relationship can be observed between $\log Q$ and Fh. Eq. (13a) fits the predictions 
shown in Fig. 9a with median rMSE Eq. (13)=43\%; Eq. (13) is an explicit estimator of horizontal wave forces on crown walls.

$$
F h=\frac{F h_{0.1 \%}}{\left(0.5 \rho g C_{h}^{2}\right)}=3.6+0.6 \cdot \log Q
$$

Assuming a Gaussian error distribution, the $90 \%$ CI associated to the estimations given by Eq. (13a) is calculated with

$$
F h \pm 0.63
$$

Fig. $9 \mathrm{~b}$ shows the predictions of the $12 \mathrm{H} 701$ model as a function of $X_{7}=\log Q$ and $X_{2}=\xi_{0 p}$, where an approximate linear relationship depending on $X_{2}=\xi_{0 p}$ is observed between $\log Q$ and Fh. Eq. (14) fits the predictions shown in Fig. 9b with median rMSE Eq. $(14)=37 \%$.

$$
F h=\frac{F h_{0.1 \%}}{\left(0.5 \rho g C_{h}^{2}\right)}=\left(0.27 \cdot \ln \left(\xi_{0 p}\right)+0.1\right)(\log Q+6)+0.23
$$

Assuming a Gaussian error distribution, the $90 \%$ CI associated to the estimations provided by Eq. (14a) is given by

$F h \pm 0.59$

Figs. $9 \mathrm{c}$ and $9 \mathrm{~d}$ shows two examples of the predictions of the $13 \mathrm{H} 701$ model as a function of $X_{7}=\log Q, X_{2}=\xi_{0 p}$, and $X_{4}=\left(R_{c}-A_{c}\right) / C_{h}$. Eq. (15) fits the predictions shown in Fig. 9c and 9d with median rMSE Eq. (15) $=35 \%$.

$$
F h=\frac{F h_{0.1 \%}}{\left(0.5 \rho g C_{h}^{2}\right)}=\left(\left(0.27 \cdot \ln \left(\xi_{0 p}\right)+0.1\right)(\log Q+6)+0.23\right)\left(0.5 \cdot \frac{\left(R_{c}-A_{c}\right)}{C_{h}}+1\right)-0.15
$$


Assuming a Gaussian error distribution, the $90 \%$ CI associated to the estimations calculated with Eq. (15a) is given by

$F h \pm 0.57$
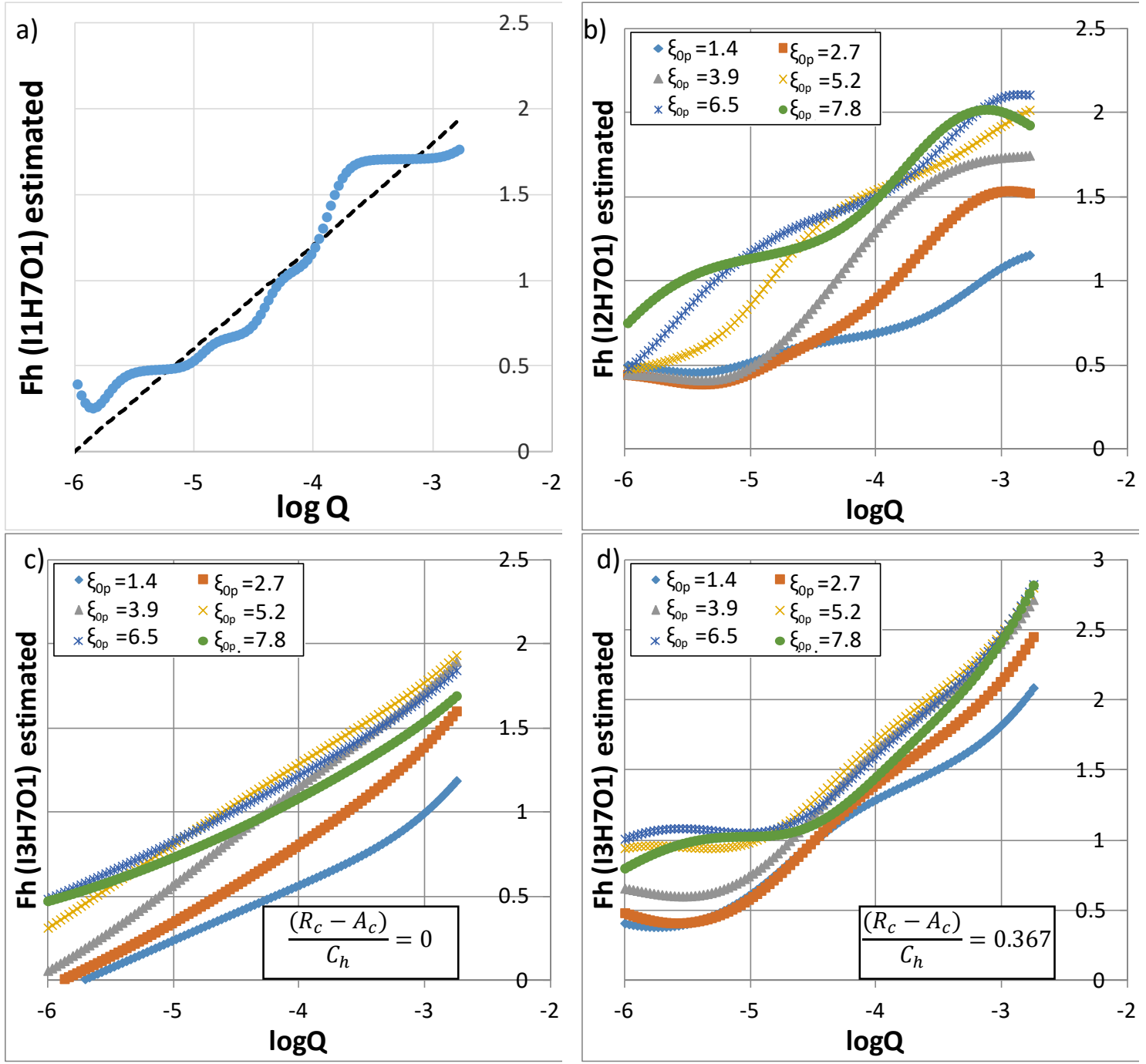

Fig. 9. Dimensionless horizontal wave forces, Fh, predicted with models: I1H7O1 (a);

$12 H 7 O 1(b)$ and $13 H 7 O 1$ (c and d).

Fig. 10 shows the goodness of fit of Eq. (15) with median $\mathrm{rMSE}_{\text {Eq.(15) }}=35 \%$. Eq. (15) is more complex than Eqs. (13) and (14), but less complex than Eqs. (9) and (11) with $\mathrm{rMSE}_{\mathrm{Eq} .(9)}=26 \%$ and $\mathrm{rMSE}_{\mathrm{Eq} .(11)}=26 \%$. 


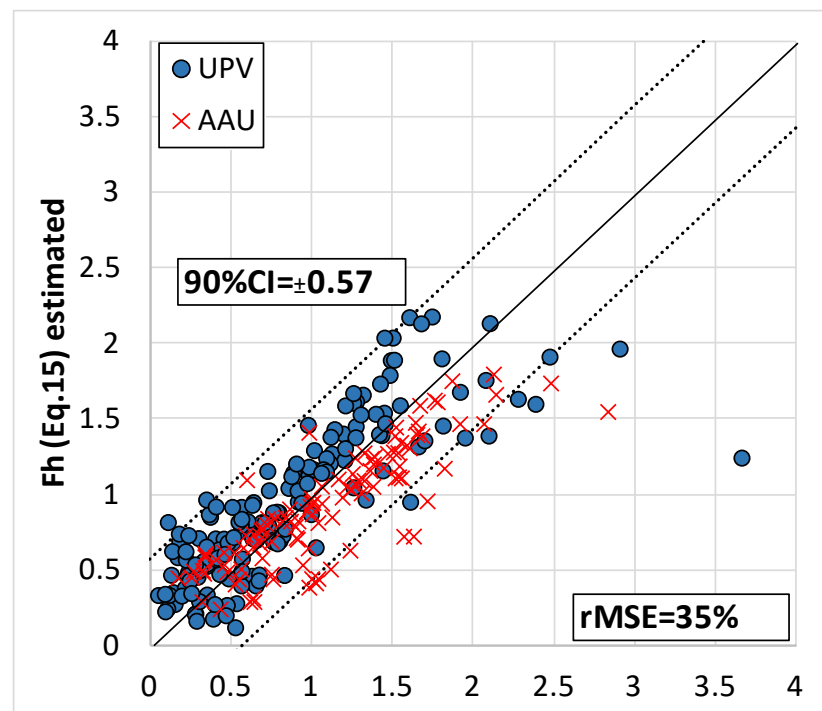

Fh measured

Fig. 10. Eq. (15) dimensionless horizontal force estimation and 90\% CI compared to measured dimensionless horizontal force. Pedersen's [2] dataset is referred to as AAU and Molines' [8] dataset is referred to as UPV.

\subsection{Estimation of up-lift pressure: $P b=P b_{0.1 \%} /\left(0.5 \rho g C_{h}\right)$.}

Table 6 and Fig. 11 show the 5\%,50\% and 95\% percentiles of the $\mathrm{rMSE}_{\text {INiH701 }}$ (test data), the $90 \%$ CI of the $\mathrm{rMSE}_{\mathrm{INiH701}}$ (test data), and the rMSE corresponding to Eq. (9) with a solid red line. The variable $X_{7}=\log Q$ was selected first as the most relevant variable in $61 \%$ of the cases; logQ explained approximately $45 \%$ of the variance of the dimensionless up-lift wave pressures, $\mathrm{Pb} . \quad \mathrm{X}_{4}=\left(R_{c}-A_{c}\right) / C_{h}$ was also a significant explanatory variable which explains an additional $22 \%$ of the variance of $\mathrm{Pb}$.

Number of input variables $(\mathrm{Ni})$ in the $\mathrm{IN}_{\mathrm{i}} \mathrm{H} 7 \mathrm{O} 1$ model

\begin{tabular}{|c|c|c|c|c|c|}
\hline & & & & \\
\hline & & 1 & 2 & 3 & 4 \\
\hline Selected variable $\left(X_{j}\right)$ & & $X_{7}=\log Q$ & $\mathrm{X}_{4}=\left(R_{c}-A_{c}\right) / C_{h}$ & $X_{5}=\sqrt{L_{m} / G_{c}}$ & $X_{6}=F_{c} / L_{o p}$ \\
\hline rMSE ${ }_{\text {INiH7O1 (test data) }}$ & $5 \%$ & $38.3 \%$ & $19.5 \%$ & $12.6 \%$ & $10.2 \%$ \\
\hline
\end{tabular}




\begin{tabular}{llllll}
\hline $50 \%$ & $54.2 \%$ & $32.2 \%$ & $24.1 \%$ & $22.2 \%$ \\
\cline { 2 - 6 } & $95 \%$ & $77.5 \%$ & $59.1 \%$ & $54.8 \%$ & $48.4 \%$ \\
\hline
\end{tabular}

Table 6. Ranking of the relevant variables affecting dimensionless up-lift pressures, $P b$.

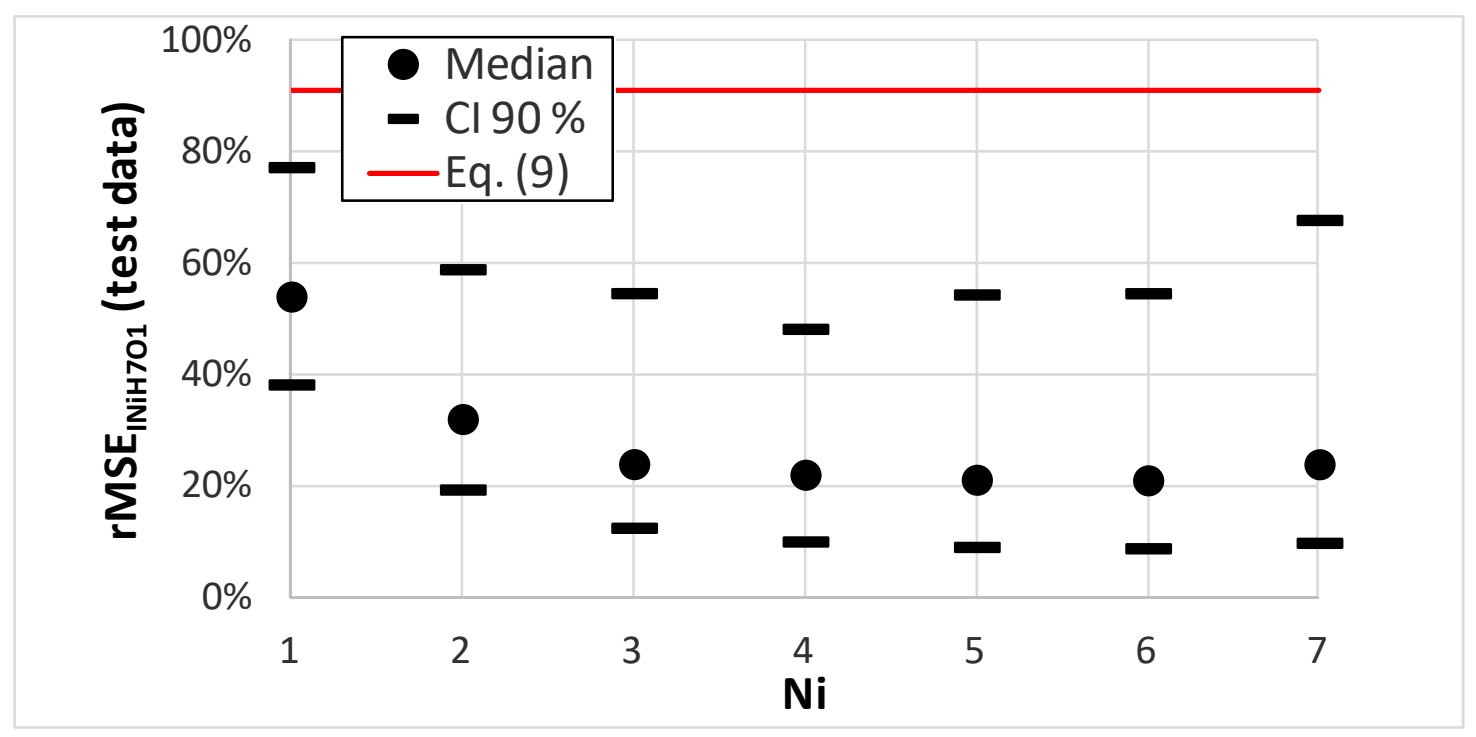

Fig. 11. Influence of the number of input variables (Ni) on the rMSE of Pb.

Analyzing Pedersen [2] experimental data, the simulations of the $11 \mathrm{H} 701$ model as a function of $X_{7}=\log Q$ showed an approximate linear relationship with $\mathrm{Pb}$. Eq. (16) with median $\mathrm{rMSE}$ Eq. (16) $=54 \%$ is proposed to estimate $\mathrm{Pb}$.

$$
P b=\frac{P b_{0.1 \%}}{\left(0.5 \rho g C_{h}\right)}=4.3+0.52 \cdot \log Q
$$

Assuming a Gaussian error distribution, the $90 \%$ CI associated to the estimations given by Eq. (16a) is calculated with

$$
P b \pm 0.74
$$

Estimations given by Eq. (16) might be improved by considering the second best additional variable listed in Table $4, \mathrm{X}_{4}=\frac{\left(R_{c}-A_{c}\right)}{C_{h}}$. Simulations conducted with the $12 \mathrm{H} 701$ 
model lead to estimations of $\mathrm{Pb}$ given by Eq. (17) with median $\mathrm{rMSE}$ Eq. (17) $=40 \%<<\mathrm{rMSE}$ Eq. $(9)=91 \%$.

$P b=\frac{P b_{0.1 \%}}{\left(0.5 \rho g C_{h}\right)}=0.9+\left(0.4 \cdot \frac{\left(R_{c}-A_{c}\right)}{C_{h}}+0.6\right) \cdot(\log Q+6)$

Assuming a Gaussian error distribution, the $90 \%$ CI associated to the estimations given by Eq. (17a) is calculated with

$P b \pm 0.64$

\subsection{Estimation of up-lift pressure: $P b F=P b F h_{0.1 \%} /\left(0.5 \rho g C_{h}\right)$.}

Table 7 and Fig. 12 illustrate the 5\%, 50\% and 95\% percentiles of the $\mathrm{rMSE}_{\mathrm{INiH701}}$ (test data), the $90 \%$ CI of the rMSEINiH701 (test data), and the rMSE provided by Eq. (11) with a dotted red line. The variable $X_{6}=F_{c} / L_{0 p}$ was selected first as the most relevant variable in $88 \%$ of the cases; $F_{c} / L_{0 p}$ explained approximately $81 \%$ of the variance of the dimensionless up-lift wave forces, $\mathrm{PbF} . \mathrm{X}_{7}=\log \mathrm{Q}$ was also a significant explanatory variable which explained an additional $6 \%$ of the variance of $\mathrm{PbF}$.

Number of input variables $(\mathrm{Ni})$ in the $\mathrm{IN}_{\mathrm{i}} \mathrm{H} 7 \mathrm{O} 1$ model

\begin{tabular}{lccccc}
\cline { 2 - 6 } & 1 & 2 & 3 & 4 \\
\hline Selected variable $\left(\mathrm{X}_{\mathrm{j}}\right)$ & & $X_{6}=F_{c} / L_{0 p}$ & $\mathrm{X}_{7}=\log$ & $X_{5}=\sqrt{L_{m} / G_{c}}$ & $\mathrm{X}_{4}=\left(R_{c}-A_{c}\right) / C_{h}$ \\
\hline \multirow{3}{*}{ rMSE $_{\text {INiH701 (test data) }}$} & $5 \%$ & $9.7 \%$ & $6.4 \%$ & $5.9 \%$ & $6.0 \%$ \\
\cline { 2 - 6 } & $50 \%$ & $18.7 \%$ & $12.4 \%$ & $11.4 \%$ & $11.8 \%$ \\
\cline { 2 - 6 } & $95 \%$ & $35.1 \%$ & $21.2 \%$ & $19.7 \%$ & $19.8 \%$ \\
\hline
\end{tabular}

Table 7. Ranking of the relevant variables affecting dimensionless up-lift pressures, $\mathrm{PbF}$. 


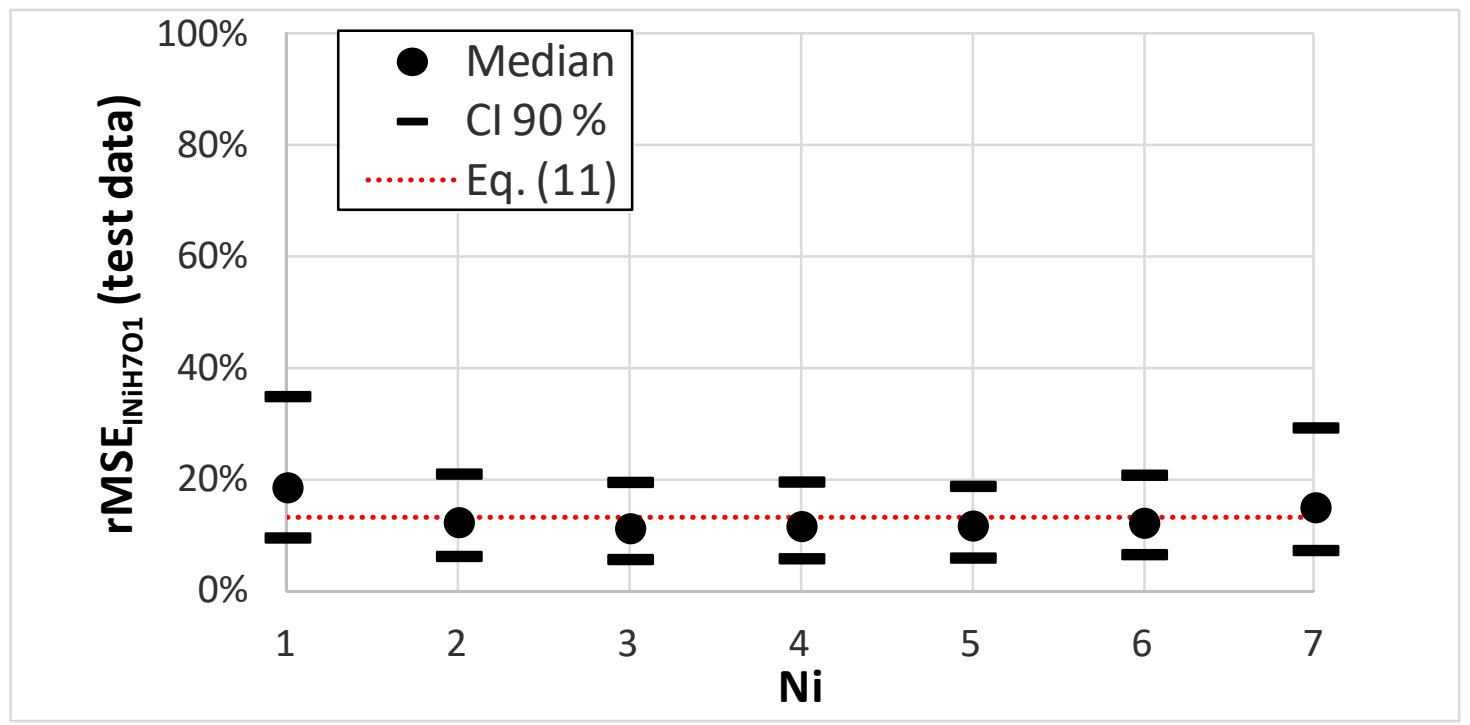

Fig. 12. Influence of the number of input variables (Ni) on the rMSE of PbF.

Analyzing Molines [8] experimental data, the simulations of the $11 \mathrm{H} 701$ model as a function of $X_{6}=F_{c} / L_{0 p}$ showed an approximate potential relationship with $\mathrm{PbF}$. Eq. (18) with median $\mathrm{rMSE}$ Eq. $(18)=30 \%$ is proposed to estimate $\mathrm{PbF}$. rMSE Eq. $(18)=30 \%$ is higher than $r M S E_{\text {Eq. }(11)}=13 \%$ but using only one single explanatory variable.

$$
P b F=\frac{P b F h_{0.1 \%}}{\left(0.5 \rho g C_{h}\right)}=0.02 \cdot\left(\frac{F_{c}}{L_{0 p}}\right)^{-1 / 2}
$$

Assuming a Gaussian error distribution, the $90 \% \mathrm{CI}$ associated to the estimations given by Eq. (18a) is calculated with

$$
P b F \pm 0.45
$$

\subsection{Estimation of overturning moments: $M h=M h_{0.1 \%} /\left(\mathrm{pgCh}^{3}\right)$.}

Table 8 and Fig. 13 illustrate the 5\%, 50\% and 95\% percentiles of the rMSE $_{\text {INiH701 (test }}$ data), the $90 \%$ CI of the $\mathrm{rMSE}_{\mid \mathrm{NiH701}}$ (test data), and the rMSE provided by Eq. (9) with a solid red line. The variable $\mathrm{X}_{7}=\log \mathrm{Q}$ was selected first as the most relevant variable in 
$67 \%$ of the cases; logQ explained approximately $54 \%$ of the variance of the dimensionless overturning moments, Mh. $\mathrm{X}_{4}=\left(R_{c}-A_{c}\right) / C_{h}$ was also a significant explanatory variable which explained an additional $22 \%$ of the variance of $\mathrm{Mh}$.

Number of input variables $(\mathrm{Ni})$ in the $\mathrm{IN}_{\mathrm{i}} \mathrm{H} 7 \mathrm{O} 1$ model

\begin{tabular}{lccccc}
\cline { 2 - 6 } & & 1 & 2 & 3 & 4 \\
\hline Selected variable $\left(\mathrm{X}_{\mathrm{j}}\right)$ & & $\mathrm{X}_{7}=\log \mathrm{Q}$ & $\mathrm{X}_{4}=\left(R_{c}-A_{c}\right) / C_{h}$ & $X_{5}=\sqrt{L_{m} / G_{c}}$ & $\mathrm{X}_{2}=\xi_{0 \mathrm{p}}$ \\
\hline \multirow{3}{*}{ rMSE $_{\text {INiH701 (test data) }}$} & $5 \%$ & $30.2 \%$ & $10.0 \%$ & $6.7 \%$ & $6.4 \%$ \\
\cline { 2 - 6 } & $50 \%$ & $46.2 \%$ & $23.8 \%$ & $16.6 \%$ & $16.6 \%$ \\
\cline { 2 - 6 } & $95 \%$ & $68.2 \%$ & $45.4 \%$ & $39.7 \%$ & $83.4 \%$ \\
\hline
\end{tabular}

Table 8. Ranking of the relevant variables affecting dimensionless overturning moments, Mh.

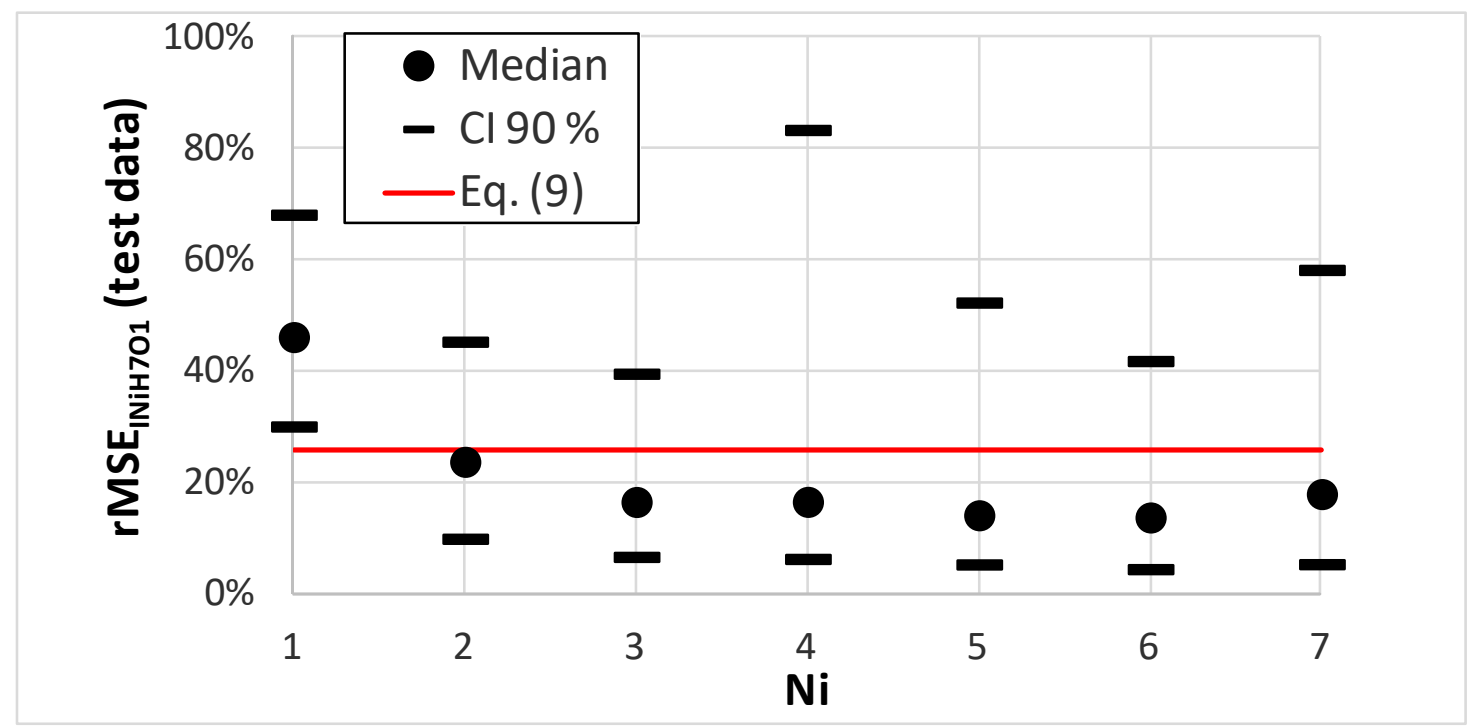

Fig. 13. Influence of the number of input variables (Ni) on the rMSE of Mh.

Analyzing Pedersen [2] experimental data, the simulations of the $11 \mathrm{H} 701$ model as a function of $X_{7}=\log Q$ showed an approximate linear relationship with Mh. Eq. (19) with median $\mathrm{rMSE}$ Eq. (19) $=54 \%$ is proposed to estimate $\mathrm{Mh}$

$$
M h=\frac{M h_{0.1 \%}}{\left(\rho g C_{h}^{3}\right)}=0.7+0.11 \cdot \log Q
$$


Assuming a Gaussian error distribution, the $90 \%$ CI associated to the estimations provided by Eq. (19a) is given by

$$
M h \pm 0.14
$$

Estimations given by Eq. (19a) might be improved by considering the second best

additional variable listed in Table $8, \mathrm{X}_{4}=\frac{\left(R_{c}-A_{c}\right)}{C_{h}}$. Simulations conducted with the $12 \mathrm{H} 701$ model lead to estimations of Mh given by Eq. (20) with median rMSE Eq. (20)=34\% higher than $\mathrm{rMSE} \mathrm{Eq}_{\text {( }(9)}=\mathbf{2 6 \%}$ but using only two explanatory variables.

$M h=\frac{M h_{0.1 \%}}{\left(\rho g C_{h}^{3}\right)}=0.15+\left(0.3 \cdot \frac{\left(R_{c}-A_{c}\right)}{C_{h}}+0.09\right) \cdot(\log Q+5)$

Assuming a Gaussian error distribution, the $90 \%$ CI associated to the estimations given by Eq. (20a) is calculated with

$M h \pm 0.12$

\subsection{Estimation of overturning moments: $M h F=M h F h_{0.1 \%} /\left(\rho g C_{h}{ }^{3}\right)$.}

Table 9 and Fig. 14 illustrate the 5\%, 50\% and 95\% percentiles of the MSSE $_{\text {INiH701 }}$ (test

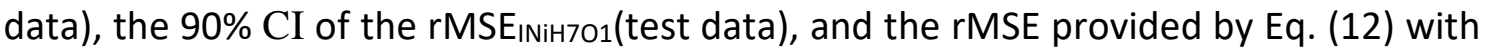
a dotted red line. The variable $X_{7}=\log Q$ was selected first as the most relevant variable in $79 \%$ of the cases; $\log Q$ explained approximately $60 \%$ of the variance of the dimensionless overturning moments, MhF. $\mathrm{X}_{4}=\left(R_{c}-A_{c}\right) / C_{h}$ was also a significant explanatory variable which explained an additional $6 \%$ of the variance of MhF. 
Number of input variables $(\mathrm{Ni})$ in the $\mathrm{IN}_{\mathrm{i}} \mathrm{H} 7 \mathrm{O} 1$ model

\begin{tabular}{lccccc}
\cline { 2 - 6 } & & 1 & 2 & 3 & 4 \\
\hline Selected variable $\left(\mathrm{X}_{\mathrm{j}}\right)$ & & $\mathrm{X}_{7}=\log \mathrm{O}$ & $\mathrm{X}_{4}=\left(R_{c}-A_{c}\right) / C_{h}$ & $X_{3}=\gamma_{\mathrm{f}} R_{u 0.1 \%} / R_{c}$ & $X_{5}=\sqrt{L_{m} / G_{c}}$ \\
\hline \multirow{3}{*}{ rMSE ${ }_{\text {INiH701 (test data) }}$} & $5 \%$ & $22.1 \%$ & $19.0 \%$ & $18.8 \%$ & $18.5 \%$ \\
\cline { 2 - 6 } & $50 \%$ & $39.4 \%$ & $34.3 \%$ & $36.3 \%$ & $31.8 \%$ \\
\cline { 2 - 6 } & $95 \%$ & $61.2 \%$ & $56.7 \%$ & $51.9 \%$ & $52.6 \%$ \\
\hline
\end{tabular}

Table 9. Ranking of relevant variables affecting dimensionless overturning moments,

MhF.

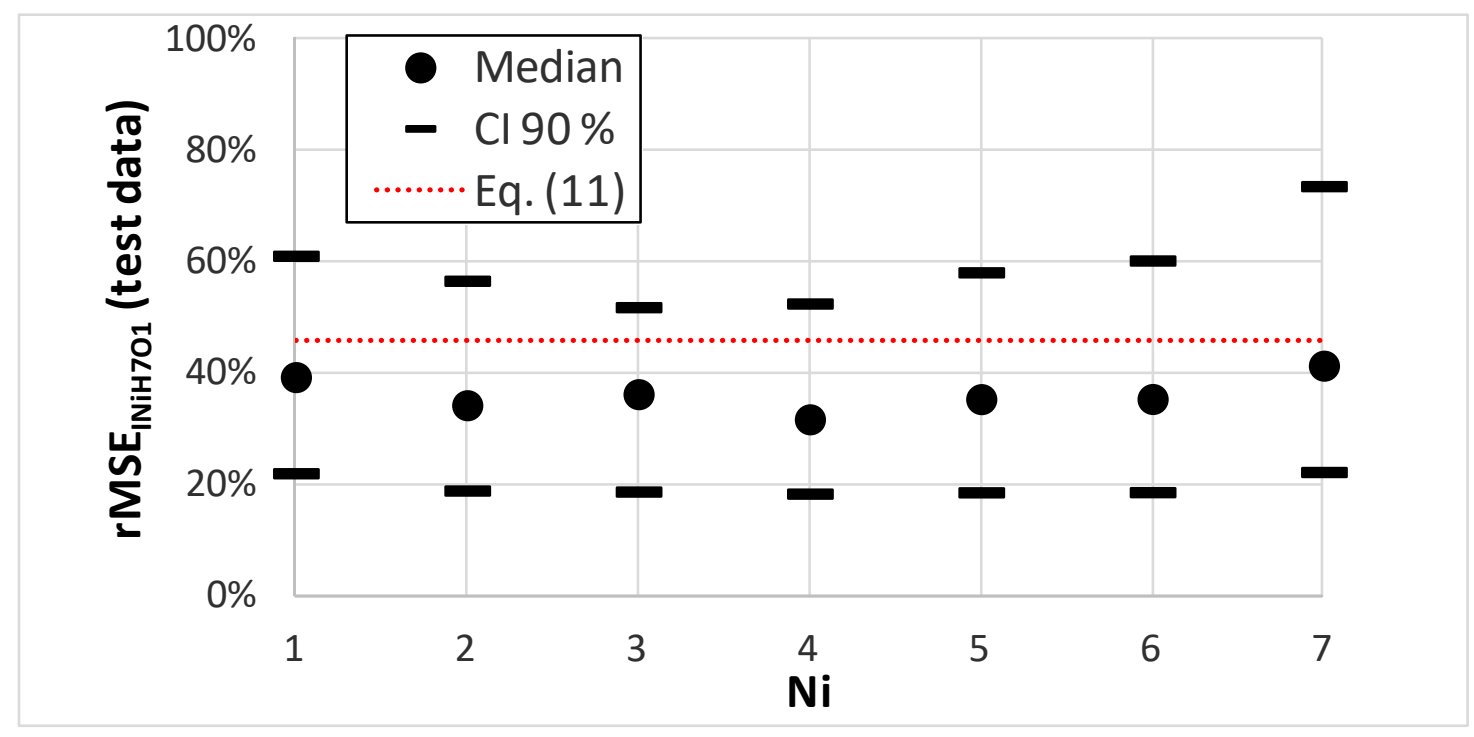

Fig. 14. Influence of the number of input variables (Ni) on the rMSE of MhF.

Analyzing Molines [8] experimental data, the simulations of the $11 \mathrm{H} 701$ model as a function of $X_{7}=\log Q$ showed an approximate linear relationship with MhF. Eq. (21) with median $r M S E_{\text {Eq. }}(21)=43.3 \%$ is proposed to estimate MhF. $r M S E$ Eq. (21) $=43 \%$ is lower than rMSE Eq. (11) $=46 \%$.

$$
M h F=\frac{M h_{(F h 0.1 \%)}}{\left(\rho g C_{h}^{3}\right)}=1.08+0.18 \cdot \log Q
$$


Assuming a Gaussian error distribution, the $90 \%$ CI associated to the estimations given by Eq. (21a) is calculated with

$$
M h F \pm 0.19
$$

\section{Wave forces on crown walls using predicted wave overtopping}

The predictions of the wave force estimations in this study were highly dependent on the overtopping discharges. If wave overtopping measurements were not available, wave forces on crown walls could be calculated using Eqs. (1) to (6) or the CLASH Neural Network to estimate wave overtopping. Table 10 shows the median rMSE on measured logQ and dimensionless wave forces using Eqs. (13), (16), (18), (19) and (21) with overtopping predictions given by Eqs. (1) to (6) and the CLASH Neural Network. Eqs. (13), (16), (18), (19) and (21) used only one explanatory variable, logQ or $F_{c} / L_{0 p}$. Table 10 indicates the source of data, estimated dimensionless variable $(\log \mathrm{Q}, \mathrm{Fh}, \mathrm{Pb}$, $\mathrm{PbF}, \mathrm{Mh}$ or $\mathrm{MhF})$, input variable and equation number to estimate wave forces, median rMSE of wave force estimation based on wave overtopping estimators given by Eqs. (1) to (6) and the CLASH Neural Network, and rMSE of wave force estimations using Eqs. (9) and (11). The far right column in Table 10 shows the median rMSE of predicted wave forces and moments on the crown wall using the I1H701 model (test data) used to develop Eqs. (13), (16), (18), (19) and (21). 


\begin{tabular}{|c|c|c|c|c|c|c|c|c|c|c|c|c|c|}
\hline \multirow[b]{2}{*}{$\begin{array}{l}\frac{\pi}{0} \\
\frac{\pi}{0} \\
4 \\
0 \\
0 \\
0 \\
\frac{0}{3} \\
0 \\
0\end{array}$} & \multirow[b]{2}{*}{ 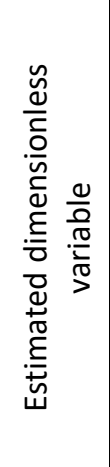 } & \multirow[b]{2}{*}{ 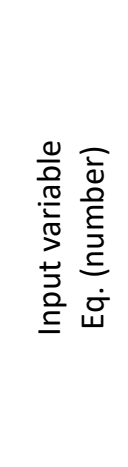 } & \multicolumn{7}{|c|}{$\begin{array}{l}\text { Wave force estimation based on wave overtopping } \\
\text { predictions }\end{array}$} & \multicolumn{4}{|c|}{ Wave force estimation } \\
\hline & & & 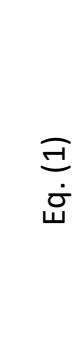 & 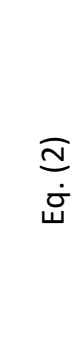 & $\begin{array}{l}\bar{m} \\
\dot{\dot{m}}\end{array}$ & $\begin{array}{l}\check{\Xi} \\
\dot{\dot{\Psi}}\end{array}$ & $\begin{array}{l}\text { ஸே } \\
\dot{\dot{\varphi}}\end{array}$ & $\begin{array}{l}\bar{\theta} \\
\dot{\dot{u}}\end{array}$ & 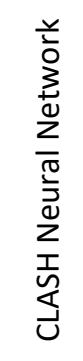 & 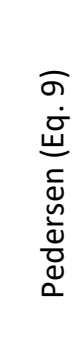 & 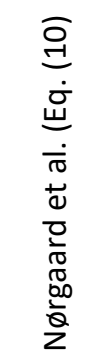 & 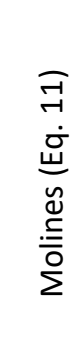 & $\begin{array}{l}\text { 모 } \\
\text { I1 } \\
\text { 트 }\end{array}$ \\
\hline $\begin{array}{l}\text { AAU \& } \\
\text { UPV }\end{array}$ & $\log (\mathrm{Q})$ & - & $>1$ & $>1$ & 0.71 & 0.39 & $>1$ & 0.37 & 0.22 & - & - & - & - \\
\hline $\begin{array}{l}\text { AAU \& } \\
\text { UPV }\end{array}$ & Fh & $\begin{array}{l}\log Q \\
\text { Eq.(13) }\end{array}$ & 0.88 & $>1$ & 0.82 & 0.41 & 0.93 & 0.44 & 0.40 & 0.26 & 0.34 & 0.26 & 0.41 \\
\hline AAU & $\mathrm{Pb}$ & $\begin{array}{l}\log Q \\
\text { Eq.(16) }\end{array}$ & $>1$ & $>1$ & $>1$ & 0.63 & $>1$ & 0.67 & 0.58 & 0.91 & 0.91 & - & 0.54 \\
\hline UPV & $\mathrm{PbF}$ & $\begin{array}{l}\mathrm{F}_{\mathrm{c}} / \mathrm{L}_{\mathrm{op}} \\
\text { Eq.(18) }\end{array}$ & 0.30 & 0.30 & 0.30 & 0.30 & 0.30 & 0.30 & 0.30 & - & - & 0.13 & 0.19 \\
\hline AAU & $\mathrm{Mh}$ & $\begin{array}{l}\log Q \\
\text { Eq.(19) }\end{array}$ & 0.97 & 0.92 & 0.94 & 0.53 & $>1$ & 0.60 & 0.49 & 0.26 & 0.37 & - & 0.46 \\
\hline UPV & $\mathrm{MhF}$ & $\begin{array}{c}\log Q \\
\text { Eq.(21) }\end{array}$ & 0.59 & $>1$ & 0.56 & 0.35 & 0.65 & 0.49 & 0.46 & - & - & 0.46 & 0.39 \\
\hline
\end{tabular}

Table 10. Median rMSE corresponding to different wave overtopping and wave force

estimators. Pedersen's [2] dataset is referred to as AAU and Molines' [8] dataset is

referred to as UPV.

The CLASH Neural Network provided the best overtopping estimations for Pedersen [2] and Molines [8] data, and the best wave force and overturning moment estimations based on wave overtopping. The rMSE of wave force and moment estimations using the predicted overtopping discharges given by the CLASH Neural Network were only slightly higher than those corresponding to the specific formulas given by Eqs. (9), (10) and (11) to calculate wave forces on the crown wall. The reliability of estimated wave forces and moments on the crown wall using Eqs. (13) to (21) based on measured logQ depends on the accuracy of wave overtopping predictions. 
Eqs. (13), (16), (18), (19) and (21) allow for an easy estimation of wave forces on crown walls based on $\log Q$ and $F_{c} / L_{0 p}$. They make it clear that higher dimensionless overtopping rates inevitably generate higher dimensionless wave forces on crown walls. Using measured $\log Q$, the new wave force and overturning moment estimators have $30 \%<\mathrm{rMSE}<54 \%$, slightly higher than $26 \%<\mathrm{rMSE}<91 \%$ from the formulas given by Pedersen [2], 34\%<rMSE $<91 \%$ from the formulas given by Nørgaard et al. [24] and $13 \%<\mathrm{rMSE}<46 \%$ from the formulas given by Molines [8]. The new estimators based on $\log Q$ have fewer parameters, are easier to use and can use logQ recorded from smallscale tests or prototypes which implicitly take into account core permeability and other structural characteristics not considered in the predicting formulas.

\section{Sensitivity to wave overtopping of wave forces and overturning moments on crown walls}

The wave forces and moments on crown walls are sensitive to wave overtopping. In this section the force estimators, Eqs. (13), (16), (18), (19) and (21), are analyzed. Fig. 15 illustrates the variation in dimensionless wave forces on the crown wall depending on wave overtopping discharges. The slopes of the lines in Fig. 15 are $\mathrm{dFh} / \mathrm{d}(\log Q)=0.60 ; \mathrm{dPb} / \mathrm{d}(\log Q)=0.52 ; \mathrm{dMh} / \mathrm{d}(\log Q)=0.11$ and $\mathrm{dMhF} / \mathrm{d}(\log Q)=0.18 . \mathrm{PbF}$ is highly dependent on $F_{c} / L_{0 p}$ and only slightly dependent on logQ (see Table 7) 


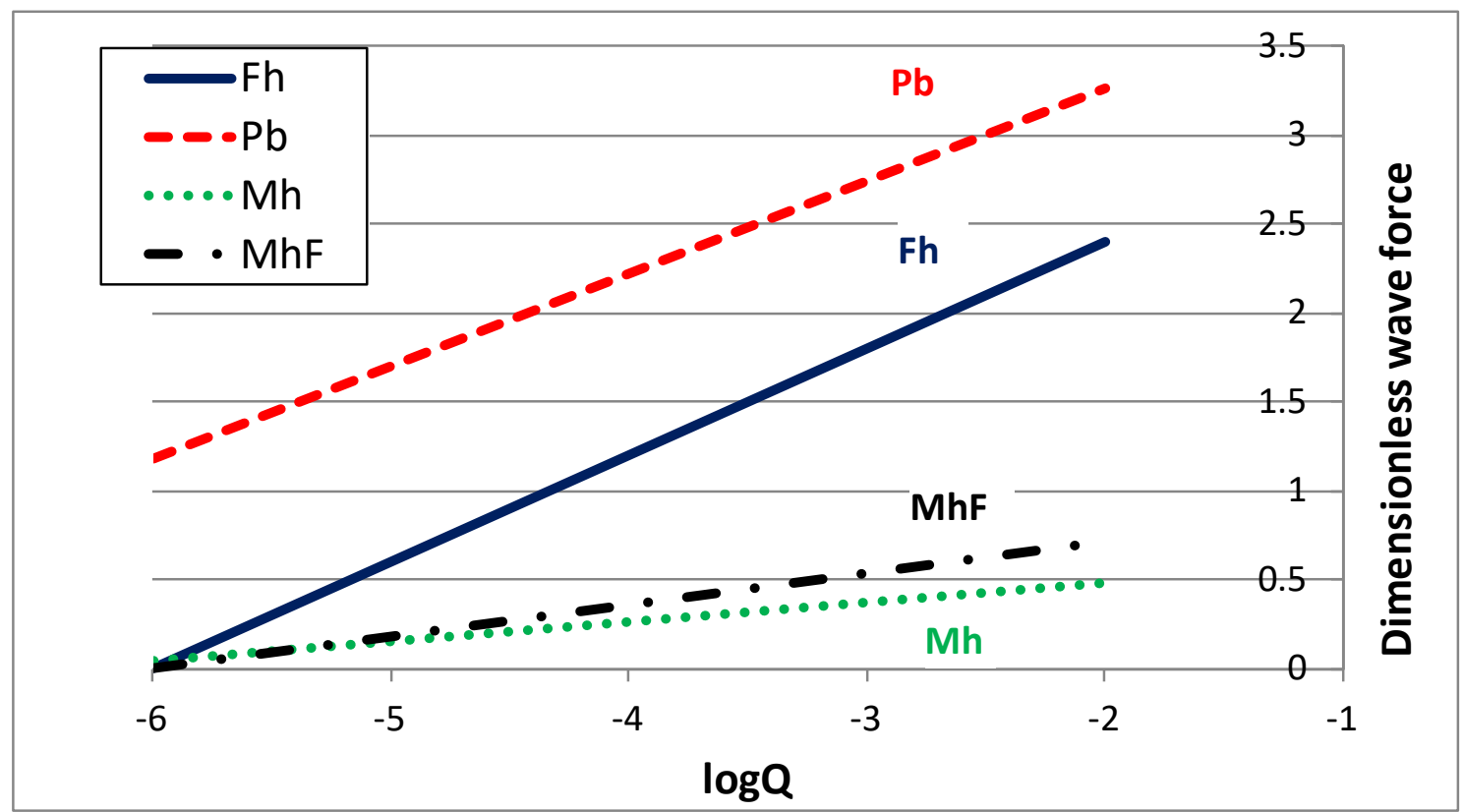

Fig. 15. Sensitivity of dimensionless wave forces on crown walls to wave overtopping discharges.

If wave overtopping is one order of magnitude higher, the wave forces and overturning moments on the crown wall $\mathrm{Fh}, \mathrm{Pb}, \mathrm{Mh}$ and $\mathrm{MhF}$ increase $60 \%, 52 \%, 11 \%$ and $18 \%$, respectively. For the preliminary design, Fig. 15 can be used as a design graph to estimate $\mathrm{Fh}_{0.1 \%}, \mathrm{~Pb}_{0.1 \%}, \mathrm{Mh}_{0.1 \%}$, and $\mathrm{MhFh}_{0.1 \%}$ using only dimensionless mean wave overtopping discharges, $\log Q$, and crown wall height, $\mathrm{C}_{\mathrm{h}}$. To estimate $\mathrm{PbFh}_{0.1 \%}$, Eq. (18) requires using $F_{c} / L_{o p}$ and $C_{h}$

\section{Example of application}

Eqs. (13), (16), (18), (19) and (21) allow for the analysis of the influence of geometrical changes in the cross section of a mound breakwater on wave forces on crown walls. Analyzing a case similar to that described by EurOtop [10], with parameters (see Fig. 1): $\beta=0^{\circ} ; H_{m 0}(\mathrm{~m})=5 ; T_{-1,0}(\mathrm{~s})=9 ; R_{c}(\mathrm{~m})=5 ; A_{c}(\mathrm{~m})=4 ; G_{c}(\mathrm{~m})=5 ; F_{c}(\mathrm{~m})=1 ; \cot \alpha=1.5 ; \gamma_{\mathrm{f}}$ [cube, 2Layers, randomly-placed] $=0.53$ and $h(m)=12$ with toe berm $\left(B_{t}(m)=4\right.$ and $\left.h_{t}(m)=9\right)$, 
the overtopping discharge predicted by the CLASH Neural Network is $q(\mathrm{l} / \mathrm{s} / \mathrm{m})=85$. Two scenarios are considered in Fig. 16 to reduce overtopping discharges in the initial design: (1) higher crown wall freeboard $\left(R_{c}\right)$ and (2) wider armor crest berm $\left(G_{c}\right)$. Fig. 16 illustrates the variation in wave overtopping and $\mathrm{Fh}_{0.1 \%}$ with Eq.(13) and $\mathrm{Pb}_{0.1 \%}$ with Eq.(16) for both scenarios. Fig. 16a shows that increasing $R_{c}$ considerably reduces wave overtopping while it greatly increases wave forces on crown walls. Fig. $16 \mathrm{~b}$ shows that increasing $\mathrm{G}_{\mathrm{c}}$ reduces both wave overtopping and wave forces on crown walls.
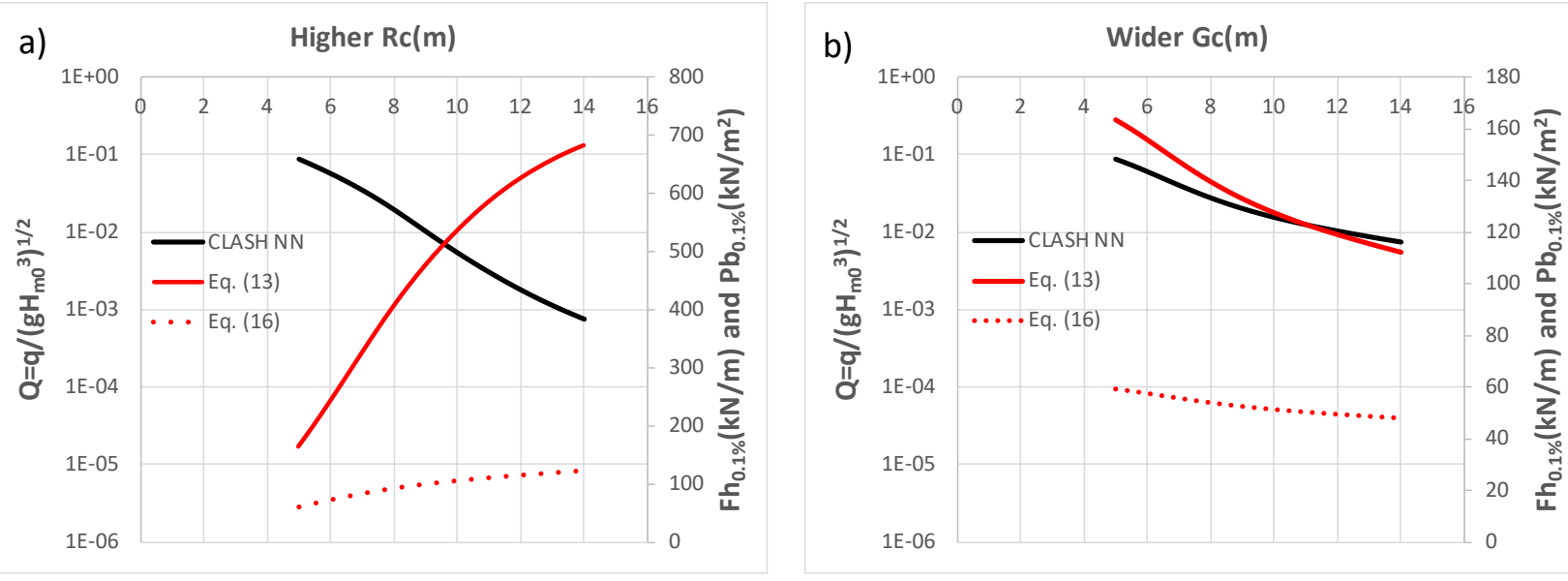

Fig. 16. Sensitivity to overtopping rates and wave forces on crown walls of a) increasing $R_{c}$ and $b$ ) increasing $G_{c}$. CLASHNN identifies the CLASH Neural Network (see Van Gent et al. [6]).

Although dimensional horizontal force $\mathrm{Fh}_{0.1 \%}$ increases when $\mathrm{Rc}$ increases, dimensionless horizontal force given by Eq. 11 decreased as well as logQ.

\section{Conclusions}

This study describes a neural network methodology to rank the influence of seven candidate input variables, including dimensionless wave overtopping discharge (logQ), to estimate dimensionless wave forces and overturning moments on crown walls. This 
methodology was applied to 274 small-scale tests carried out by Pedersen [2] and Smolka et al. [12] to propose new estimators given by Eqs. (13) to (21). The new formulas obtained in this study predict wave forces and overturning moments corresponding to the methodologies of Pedersen [2] and Molines [8] but using only a few explanatory variables. The range of application of the new formulas is $1.67<R_{c} /\left(\gamma_{f}\right.$ $H_{m 0}<6.55, \quad 1.39<\xi_{0 p}<7.77, \quad 0.36<\gamma_{f} R_{u 0.1 \%} / R_{c}<1.41,0.00<\left(R_{c}-A_{c}\right) / C_{h}<0.59,2.64$ $<\sqrt{L_{m} / G_{c}}<6.54,0.00<F_{c} / L_{O p}<0.03$ and $-6.00<\log Q<-2.78$.

The mean dimensionless wave overtopping discharge, logQ, was the most relevant explanatory variable to estimate wave forces on the crown wall. Using the neural network I1H701 model, logQ explained between $45 \%$ and $60 \%$ of the variance in wave forces and overturning moments. Up-lift pressures (PbF) were highly influenced by the foundation level, $F_{c} / L_{0 p}$, which explained $81 \%$ of the variance in the data.

Using the results from 274 wave overtopping tests, the new wave force and overturning moment estimators have a relative Mean Squared Error $30 \%<r M S E<54 \%$, slightly higher than $26 \%<r M S E<91 \%, 34 \%<r M S E<91 \%$ and $13 \%<r M S E<46 \%$ of formulas given by Pedersen [2], Nørgaard et al. [24] and Molines [8], respectively.

When wave overtopping measurements are not available, overtopping predictions can be used to estimate wave forces, but new formulas are better applied when overtopping rates are measured in small-scale tests or prototypes. In this study, Eqs. (13), (16), (18), (19) and (21) were used with overtopping predictions given by Eqs. (1) to (6) and the CLASH Neural Network. The CLASH Neural Network provided the best prediction of $\log Q$ with $r M S E=22 \%$. Using the CLASH Neural Network, the median rMSE 
of wave forces and moments $\mathrm{Fh}, \mathrm{Pb}, \mathrm{PbF}, \mathrm{Mh}$ and $\mathrm{MhF}$ were $0.40,0.58,0.30,0.49$ and 0.46 , respectively.

From a conceptual point of view, the new formulas to estimate wave forces and overturning moments on crown walls proposed in this study, use the mean overtopping discharge to replace the virtual run-up as the key explanatory variable.

To measure forces on crown walls is relatively costly both at prototype and in smallscale tests; on the contrary, overtopping discharges are much easier to measure at any scale. Prototypes usually show larger than expected overtopping rates in some sections; the new formulas can help designers to re-analyze the hydraulic stability of existing crown walls based on local observations of overtopping.

The sensitivity indexes were $d F h / d(\log Q)=0.60, d P b / d(\log Q)=0.52, d P b F / d(\log Q) \approx 0$, $\mathrm{dMh} / \mathrm{d}(\log Q)=0.11$, and $d M h F / d(\log Q)=0.18$. Based on Eqs. (13) to (21), variations in $\log Q$ between designed and constructed mound breakwaters lead to variations in wave forces on the crown wall; in those cases, the stability of the crown wall should be re-analyzed. Eqs. (13) to (21) can be used to better estimate wave forces and overturning moments on crown walls when overtopping rates are measured in smallscale tests or prototypes. Considering a wider database and additional individual overtopping measurements, the new formulas may be significantly improved in the future to estimate forces on crown walls.

\section{Acknowledgments}

The authors acknowledge financial support from European FEDER and Spanish Ministerio de Economía y Competitividad (Grant BIA2015-70436-R), SATO (OHL Group) 
and CDTI (Centro para el Desarrollo Tecnológico e Industrial). The second author was funded through the FPU program (Formación del Profesorado Universitario, Grant FP2013/01872) by the Spanish Ministerio de Educación, Cultura y Deporte. The authors thank Debra Westall for revising the manuscript.

\section{$\underline{\text { References }}$}

[1] D.G. Hamilton, K.R. Hall, Preliminary analysis of the stability of rubble mound breakwater crown walls, in: Proceedings $23^{\text {rd }}$ International Conferences on Coastal Engineering (ASCE), 1992, pp. 1217-1230.

[2] J. Pedersen, Wave forces and overtopping on crown walls of rubble mound breakwaters, series paper 12, Hydraulic and Coastal Engineering Laboratory, Department of Civil Engineering, Aalborg University, Denmark, 1996.

[3] A.R. Günback, T. Göcke, Wave screen stability of rubble mound Breakwaters, in: Proceedings of the International Symposium of Maritime Structure in the Meditarrean Sea (National Technical University of Athens), 1984, pp. 2099-2112.

[4] F.L. Martín, M.A. Losada, R. Medina, Wave loads on rubble mound breakwater crown walls, Coastal Engineering 37 (1999) 149-174.

[5] V. Negro, J.S. López, J.I. Polvorinos, Comparative study of breakwater crown wallcalculation methods, Proceedings of the Institution of Civil Engineers- Maritime Engineering 166 (1) (2013) 25-41.

[6] M.R.A. Van Gent, H.F.P. Van den Boogaard, B. Pozueta, J.R. Medina, Neural network modelling of wave overtopping at coastal structures, Coastal Engineering 54 (8) (2007) 586-593. 

(accessed 25.01.2017).

[8] J. Molines, Wave overtopping and crown wall stability of cube and Cubipodarmored mound breakwaters, PhD Thesis, Universitat Politècnica de València, DOI: 10.4995/Thesis/10251/62178,

https://riunet.upv.es/bitstream/handle/10251/62178/indice\%20tesis.pdf?sequenc e=2\&isAllowed=y, 2016 (accessed 15.01.2017).

[9] J.W. Van der Meer, J.P.M. Janssen, Wave Run-Up and Wave Overtopping at Dikes, Delft Hydraulics No. 485, 1994.

[10] EurOtop, Wave Overtopping of Sea Defences and Related Structures: Assessment Manual (EurOtop Manual). T. Pullen, N.W.H. Allsop, T. Bruce, A. Kortenhaus, H. Schüttrumpf, J.W. Van der Meer, Environment Agency, UK/ENW Expertise Netwerk Waterkeren, NL/KFKI Kuratorium für Forschung im Küsteningenieurwesen, Germany, http:// www.overtopping-manual.com, 2007 (accessed 12.09.2016).

[11] P. Besley, Overtopping of sea-walls-design and assessment manual, R\&D Technical Report 178, Environment Agency, Bristol, UK, 1999.

[12] E. Smolka, G. Zarranz, J.R. Medina, Estudio Experimental del Rebase de un Dique en Talud de Cubípodos (in Spanish), in: X Jornadas Españolas de Costas y Puertos (Universidad de Cantabria-Adif Congresos), 2009, pp. 803-809.

[13] J.W. Van der Meer, T. Bruce, New Physical Insights and Design Formulas on Wave Overtopping at Sloping and Vertical Structures, Journal of Waterway, Port, Coastal and Ocean Engineering 140 (6) (2014) 04014025. 
[14] EurOtop, Manual on wave overtopping of sea defences and related structures: An overtopping manual largely based on European research, but for worldwide application, $2^{\text {nd }}$ Edition (EurOtop Manual). J.W. Van der Meer, T. Pullen, N.W.H. Allsop, T. Bruce, A. Kortenhaus, H. Schüttrumpf, http:// www.overtoppingmanual.com, 2016 (accessed 12.07.2017).

[15] Crest Level Assessment of coastal Structures by full scale monitoring, neural network prediction and Hazard analysis on permissible wave overtopping, http://www.clash.ugent.be/, 2001-2003 (accessed 12.09.2016).

[16] J. Molines, J.R. Medina, Explicit wave overtopping formula for mound breakwaters with crown walls using CLASH neural network derived-data, Journal of Waterway, Port, Coastal and Ocean Engineering 142 (3) (2016) 04015024.

[17] J. Molines, J.R Medina, Calibration of overtopping roughness factors for concrete armor units in non-breaking conditions using the CLASH database, Coastal Engineering 96 (2015) 65-70.

[18] V. Negro, J.S. López, J.I. Polvorinos, J. Molines, Discussion: Comparative study of breakwater crown wall - calculation methods, Proceedings of the Institution of Civil Engineers- Maritime Engineering 167(3) (2014) 154-155.

[19] J. Molines, Stability of mound breakwater crown walls armoured with cubes and Cubipods, PIANC e-Magazine On Course 143 (2011) 29-11.

[20] U.S. Army Corps of Engineers (USACE), Part VI Chapter 5: Fundamentals of design, in: USACE, Coastal Engineering Manual, Engineer Manual 1110-2-1100, Washington, D.C., 2002. 
[21] O.J. Jensen, A monograph of rubble mound breakwaters, Danish Hydraulic Institute, Hórsholm, Denmark, 1984.

[22] J.W. Van der Meer, C.J.M. Stam, Wave run-up on smooth and rock slopes, Journal of Waterway, Port, Coastal, and Ocean Engineering 188 (5) (1992) 534-550.

[23] M.A. Losada, L.A. Gimenez-Curto, Flow characteristics on rough, permeable slopes under wave action, Coastal Engineering 4 (1981) 187-206.

[24] J.Q.H. Nørgaard, T. Lykke-Andersen, H.F. Burcharth, Wave loads on rubble mound breakwater crown walls in deep and shallow-water wave conditions, Coastal Engineering 80 (2013) 137-147.

[25] J.M. Garrido, J.R. Medina, New neural network-derived empirical formulas for estimating wave reflection on Jarlan-type breakwaters, Coastal Engineering 62 (2012) 9-18.

[26] MATLAB ${ }^{\oplus}$ 2015a, The MathWorks Inc., Natick, MA, 2015. 